\title{
Microstructure evolution and deformation texture during rolling of TIMETAL®407
}

DOI:

10.1016/j.mtla.2020.100596

10.1016/j.mtla.2020.100596

\section{Document Version}

Accepted author manuscript

Link to publication record in Manchester Research Explorer

\section{Citation for published version (APA):}

Singh, G., Fonseca, J. Q. D., \& Preuss, M. (2020). Microstructure evolution and deformation texture during rolling of TIMETAL $\otimes^{8} 407$. Materialia, 9. https://doi.org/10.1016/j.mtla.2020.100596,

https://doi.org/10.1016/j.mtla.2020.100596

\section{Published in:}

Materialia

\section{Citing this paper}

Please note that where the full-text provided on Manchester Research Explorer is the Author Accepted Manuscript or Proof version this may differ from the final Published version. If citing, it is advised that you check and use the publisher's definitive version.

\section{General rights}

Copyright and moral rights for the publications made accessible in the Research Explorer are retained by the authors and/or other copyright owners and it is a condition of accessing publications that users recognise and abide by the legal requirements associated with these rights.

\section{Takedown policy}

If you believe that this document breaches copyright please refer to the University of Manchester's Takedown Procedures [http://man.ac.uk/04Y6Bo] or contact uml.scholarlycommunications@manchester.ac.uk providing relevant details, so we can investigate your claim.

\section{OPEN ACCESS}




\title{
Microstructure evolution and deformation texture during rolling of TIMETAL ${ }^{\circledR} \mathbf{4 0 7}$
}

\author{
Gaurav Singh $^{1 *}$, J. Quinta da Fonseca, M. Preuss \\ The University of Manchester, School of Materials, Manchester M13 9PL, UK
}

\begin{abstract}
TIMETAL ${ }^{\circledR} 407$ (referred as Ti407 here afterwards) is a new titanium alloy primarily developed for combining high formability with improved strength compared to commercially pure titanium. In this study, the evolution of microstructure, spherodization behavior of $\alpha$ laths, macro and micro textures during rolling of Ti407 are examined. For this purpose, Ti407 with transformed $\beta$ microstructure was rolled at 650 and $820{ }^{\circ} \mathrm{C}$ to 50 and $75 \%$ reduction ratios followed by recrystallization heat treatment at $820{ }^{\circ} \mathrm{C}$. The material was characterized focusing on microstructure morphology and texture evolution. The material rolled at $650{ }^{\circ} \mathrm{C}$ displayed strong basal pole concentrations towards the normal direction (ND) $/ 30^{\circ}$ towards transverse direction (TD) together with a weak transverse component. When the material was rolled at higher temperature $820^{\circ} \mathrm{C}$, the texture only showed a weak transverse type texture. Complete spherodization of the $\alpha$ laths occurred only when the material was rolled to $75 \%$ reduction at $650{ }^{\circ} \mathrm{C}$. At other rolling temperature and reduction ratios, the extent of spherodization per se was limited. Our results clearly show that activation of deformation twinning in the material rolled at $650{ }^{\circ} \mathrm{C}$ to $75 \%$ reduction played a key role in the break-up of $\alpha$ laths and significant texture change involving formation of strong 30 degree basal texture component. The spherodization behavior of $\alpha$ laths in Ti407 is compared with Ti-6Al-4V rolled to equivalent temperatures relative to the $\beta$-transus based on classical boundary splitting and termination migration mechanisms.
\end{abstract}

Keywords - Titanium alloys; Texture; Rolling; Thermo-mechanical processing; Annealing; Spherodization.

\footnotetext{
$1^{*}$ Corresponding author: Gaurav Singh; Email-gauravsingh90@gmail.com; Tel: +44-(0)-161-3063601
} 


\section{Introduction}

\subsection{Background of Ti407}

Titanium alloy Ti407 (Ti-4V-0.8Al-0.08Fe-0.2Si in wt.\%) is an $\alpha+\beta$ alloy developed by TIMET with moderate strength, excellent machinability and ductility [1]. In order to achieve these goals, the alloy was designed by starting with similar base Ti-4V as Ti-6Al-4V to retain $\beta$ phase at room temperature but with lower Al content $(\sim 0.8$ wt.\%). Reducing Al content in near- $\alpha$ or $\alpha+\beta$ alloys like Ti407 promotes twinning $[2,3]$, which in turn improves formability and impact resistance as it increases the work hardening rate during deformation [4]. Moreover, reducing Al content improves ductility [5] and machinability of Ti alloys [6]. $\beta$-eutectoid elements like Si and Fe are also added to provide some solid solution strengthening.

Production scale tensile properties like ultimate tensile strength (UTS) and elongation-to-failure values of Ti407 alloy are compared with other commercially available titanium alloys like CP-Ti (Grade 1), Ti-3Al-2.5V and Ti-6Al-4V in Fig. 1 $[1,7]$. The UTS of Ti407 is greater than CP-Ti and Ti-3Al-2.5V alloys but lower than Ti-6Al-4V. On the other hand, elongation-to-failure is much higher ( $24 \%)$ than Ti6Al-4V $(\sim 14 \%)$ and comparable with CP-Ti. Thus, this alloy can be targeted as a direct replacement of $\mathrm{CP}-\mathrm{Ti}$ and $\mathrm{Ti}-3 \mathrm{Al}-2.5 \mathrm{~V}$ alloys. If strength is not a stringent design criterion, this alloy can also replace Ti-6Al-4V with improved formability and machinability.

\subsection{Thermo-mechanical processing}

The thermo-mechanical processing (TMP) route of titanium alloys determines its microstructure and crystallographic texture [8-10] and must be controlled to achieve optimum combination of mechanical properties [11-13]. One such important step during TMP of titanium alloys involves breakdown of the original $\alpha$-lamellar structure into equiaxed (or globular) form. This microstructure offers improved high-cycle fatigue strength, superplasticity and ductility and is thus more desirable for many service applications [7,13]. The process of conversion of lamellar $\alpha$ into globular form is commonly known as spherodization and can be achieved dynamically during deformation or statically during post deformation annealing treatment. The extent of spherodization depends upon the applied level of strain [14], deformation mode [15], the temperature of deformation, hold time at the deformation temperature, annealing temperature and strain path [16-20]. It has been reported that the level of strain 
required to produce fully spherodized microstructure during dynamic deformation is high $\sim 2.5-3[17,21,22]$. Further, with decreasing deformation temperature, the level of strain required to achieve complete dynamic spherodization will increase [21]. However, such high levels of strains are rarely encountered during conventional mill practices, which usually involve multipass operations with small reduction per pass and reheating steps and/or post annealing treatment. Thus, static spherodization during annealing is an essential step for obtaining a spherodized structure.

The present work is thus aimed at determining the effect of varying TMP parameters like reduction ratio and temperature on the microstructure and texture evolution, and the spherodization behavior of this new $\alpha+\beta$ Ti407 alloy. Ti407 in starting $\beta$-annealed condition was unidirectionally rolled at $650{ }^{\circ} \mathrm{C}$ (in $\alpha$ dominated phase with $\sim 75$ vol. $\% \alpha$ phase) and $820{ }^{\circ} \mathrm{C}$ (high $\alpha+\beta$ phase regime, i.e., $\sim 50$ vol. $\% \beta$ phase) to various reduction ratios. These two temperature regimes encompasses entire secondary hot-working processing window in the $\alpha+\beta$ phase field for Ti407. Rolling was selected to simulate a typical multipass breakdown operation. Following rolling or post-rolling annealing treatment, optical metallography and electron back-scatter diffraction (EBSD) analysis were carried out to determine the extent of spherodization at various temperatures and reduction ratios and the evolution of macro and micro textures. The static spherodization behavior of Ti407 during post-annealing treatment was interpreted based on various mechanisms of fragmentation and spherodization. Next, the processing response of Ti407 during rolling was compared with the $\alpha+\beta$ titanium alloy $\mathrm{Ti}-6 \mathrm{Al}-4 \mathrm{~V}$ at an identical reduction ratio and equivalent temperatures relative to the $\beta$-transus. Since it is expected that Ti407 will be far more prone to deformation twinning than Ti-6Al-4V, due to its very low Al content $[2,3,23,24]$, an additional objective of the present work was to investigate potential role of deformation twinning in $\alpha$-lamellae break-up and its subsequent effect on texture evolution. The experimentally determined $\alpha$ texture is discussed in detail in terms of slip and twinning modes as well as possibility of $\beta$ rolling texture affecting $\alpha$ texture formation.

\section{Experimental procedures}

\subsection{Materials and heat-treatment}


The Ti407 material was provided in the form of $200 \times 150 \times 40 \mathrm{~mm}^{3}$ thick plate by TIMET, UK. The Ti407 plate was produced by conventional ingot metallurgy route with final processing step in the $\alpha+\beta$ phase field followed by slow cooling. The nominal chemical composition of Ti407 is listed in Table 1. The $\beta$-transus temperature, $T_{\beta}$, (at which $\alpha+\beta$ completely transforms to $\beta$ ) of Ti407 was determined by solution heat treating $10 \times 10 \times 10 \mathrm{~mm}^{3}$ specimens at temperatures in the range of $500-900{ }^{\circ} \mathrm{C}$ for $2 \mathrm{~h}$ followed by water quenching. Optical microscopy of these samples enabled the creation of a $\beta$ approach curve, Fig. 2, which provided a $T_{\beta}$ of approximately $875^{\circ} \mathrm{C}$ for Ti407.

\subsection{Rolling}

Two $50 \times 50 \times 40 \mathrm{~mm}^{3}$ blocks were sectioned from the plate. Prior to rolling, the blocks were $\beta$ heat treated at $940{ }^{\circ} \mathrm{C}$ for $1 \mathrm{~h}$ followed by slow cooling at a rate of 1 ${ }^{\circ} \mathrm{C} / \mathrm{min}$. This will be referred as homogenized condition. The microstructural parameters like prior $\beta$ grain size, $d, \alpha$ colony size, $c$, primary $\alpha$ lath size, $\lambda$, volume fraction of $\alpha, V_{\alpha}$ and $\beta$ phase, $V_{\beta}$, were determined in the homogenized condition based on the procedures described in [25]. The obtained values are listed in Table 2. The Ti407 blocks were unidirectionally rolled at $650{ }^{\circ} \mathrm{C}$ and $820^{\circ} \mathrm{C}$ to $50 \%(\sim 20 \mathrm{~mm}$, average thickness strain $=0.69)$ and $75 \%(\sim 10 \mathrm{~mm}$, average thickness strain $=1.38)$ reduction in thickness according to the schedule shown in Table 3. The blocks were lubricated and rolled using $250 \mathrm{~mm}$ diameter rolls operating at a roll surface speed of $150 \mathrm{~mm} / \mathrm{s}$. Blocks were furnace heated for $1 \mathrm{~h}$ prior to rolling at the corresponding temperatures and reheated for $3 \mathrm{~min}$ between each pass. Following rolling, blanks were air cooled to simulate industrial practice. Subsequently, after rolling to 50 and $75 \%$ reduction at the two temperatures, blanks were annealed at $820{ }^{\circ} \mathrm{C}$ for $8 \mathrm{~h}$ followed by cooling at a rate of $1{ }^{\circ} \mathrm{C} / \mathrm{min}$. The schematic representation of the rolling and annealing process employed for Ti407 is shown in Fig. 3. Note that the rolling experiments maintained rolling direction $(\mathrm{RD})$ parallel to the $\mathrm{RD}$ of the as-received plate. The acronyms used to represent the experimental conditions are, R650-50 and R650-75: rolled at $650{ }^{\circ} \mathrm{C}$ to 50 and $75 \%$ reduction in thickness, respectively; R82050 and R820-75: rolled at $820{ }^{\circ} \mathrm{C}$ to 50 and $75 \%$ reduction in thickness, respectively. The acronym RA instead of R (for example RA650-50) indicates that the material was annealed after rolling. As mentioned earlier, all annealing took place at $820{ }^{\circ} \mathrm{C}$. 


\subsection{Post characterization}

Following rolling and annealing, the microstructure was characterized and the macro and micro textures were determined. For this purpose, samples with dimensions $20 \mathrm{x}$ $10 \times 2 \mathrm{~mm}^{3}$ were extracted at different locations from the blanks at mid-thickness parallel to the rolling plane. They were prepared by standard grinding/polishing procedures and etched with Kroll's reagent $\left(2 \% \mathrm{HF}+8 \% \mathrm{HNO}_{3}+90 \%\right.$ distilled water $)$ for $8 \mathrm{~s}$ for optical microscopy examination. The macro and micro textures were quantified using EBSD. EBSD scans were performed on a field emission gun scanning electron microscope (FEI Quanta 650), equipped with a NordLYS CCD camera detector. The EBSD mapping was performed at an operating voltage of $20 \mathrm{kV}$ with a working distance of $13 \mathrm{~mm}$. For best Kikuchi pattern indexing, samples were polished with Oxide polishing suspension $\left(80 \%\right.$ colloidal silica $\left.+20 \% \mathrm{H}_{2} \mathrm{O}_{2}\right)$ for $\sim 2 \mathrm{~h}$. After Oxide polishing samples were etched for $\sim 8 \mathrm{~s}$. The entire Oxide polishing and etching cycle was repeated 2 times. For macrotexture analysis, a coarse step size of 40 $\mu \mathrm{m}$ was used to scan large areas. To obtain better statistics, neighboring areas are individually acquired and stitched together using map stitching software to generate macrotexture. The total combined area (after stitching individual maps) scanned by EBSD to generate macrotexture pole figures ranged between $70-150 \mathrm{~mm}^{2}$. This ensured sufficient number of $\alpha$ colonies are scanned such that pole figures generated through EBSD scans does not differ significantly when compared with X-ray diffraction. For microtexture analysis an area covering $\sim 0.02-0.5 \mathrm{~mm}^{2}$ was scanned using much finer step sizes of 0.8-1.2 $\mu \mathrm{m}$. Analysis of the EBSD data was performed using HKL Channel 5 software package. Due to small size and low volume fraction of the retained $\beta$ phase (in rolled and annealed conditions), only hcp- $\alpha$ phase was indexed. The volume fraction of detected twins, $V_{T}$, was determined using stereological analysis on images obtained using optical microscopy. The area fraction of twins, assumed to be equivalent to $V_{T}$ was measured using point count technique where images were laid with rectangular grid of points. Intersections of the twins with points were marked and counted. The $V_{T}$ was calculated as, $V_{T}=$ number of intersection points / total number of points.

To determine the fraction of spherodized primary $\alpha$ lath, $\alpha_{\mathrm{p}}$, the average aspect ratio of $\sim 400$ to $600 \alpha$ platelets were measured automatically on optical micrographs using Sigma Scan Pro 4 image analyzer software. In the present work, $\alpha$ platelets with aspect (length-to-thickness) ratio less than 3 are considered as spherodized. The value 
of 3 is selected based on another spherodization study on $\alpha+\beta$ alloy Ti-6Al-2Sn-4Zr6Mo [26].

The evolution of orientation gradient in rolled samples was further studied using local misorientation analysis tool - kernel average misorientation (KAM). The local variation in orientation gradient is a good indicator of strain in the polycrystalline material and thus of the stored energy. KAM is defined as the average of misorientation between the pixel of interest at the center of the kernel and all the specified nearest neighbor pixels. KAM maps were obtained using a step size of 0.2 $\mu \mathrm{m}$ with $5 \times 5$ filter size and maximum tolerance angle of $1^{\circ}$. KAM parameters were carefully chosen such that the kernel step size of $0.2 \mu \mathrm{m}$ is much smaller than the subgrain size $(<1 \mu \mathrm{m})$ and the KAM calculation excludes contribution from grain boundaries.

The $\alpha$ orientation maps obtained in the RA650-50, RA650-75, RA820-50 and RA820-75 annealed conditions were also used to reconstruct $\beta$ grain maps based on the Burgers orientation relationship (BOR) between parent $\beta$ and daughter $\alpha$ phase. For this purpose, $\beta$ grain reconstruction software developed at the University of Sheffield within IMMPETUS was utilized. It compares orientation of individual $\alpha$ lamellae with most likely parent $\beta$ orientation between appropriate neighbors with misorientation tolerance angle set as $3^{\circ}$. More details can be found elsewhere [27-29].

\section{Results}

\subsection{Homogenized condition}

Representative low and high magnification micrographs of Ti407 in homogenized condition are illustrated in Figs. 4(a) and (b), respectively, and exhibit the expected lamellar microstructure. The prior $\beta$ grains are easily identified by the formation of discontinuous network of grain boundary $\alpha$ phase at the prior $\beta$ grain boundaries (indicated with arrow in Fig. $4 \mathrm{a}$ ). This grain boundary $\alpha$ phase is typically $6-9 \mu \mathrm{m}$ in thickness. Within each prior $\beta$ grain several $\alpha$ colonies form through nucleation and growth mechanism. The $V_{\alpha}$ and $V_{\beta}$ phase were 85 and $15 \%$, respectively. The average values of $d, c$ and $\lambda$ were 1200, 240 and $10.7 \mu \mathrm{m}$, respectively (Table 2).

The $\{0002\} \alpha$-phase pole figure (PF) of Ti407 in homogenized condition is shown in Figs. 4(c). The $\{0002\} \alpha$-phase PF revealed an almost random texture with values not exceeding $2.5 \mathrm{x}$ random, see Fig. $4(\mathrm{c})$. The $2.5 \mathrm{x}$ random is related to three $\{0002\}$ components with one of them towards TD. 


\subsection{Microstructures}

The microstructures of Ti407 in as-rolled conditions are illustrated in Figs. 5. Conditions R820-50 and R820-75 showed evidence of very fine secondary alpha, $\alpha_{s}$, formed during cooling from the rolling temperature of $820^{\circ} \mathrm{C}$, see Figs. 5(c) and (d). These $\alpha_{\mathrm{s}}$ laths were absent when the alloy was rolled at lower rolling temperature of $650{ }^{\circ} \mathrm{C}$, see Figs. 5(a) and (b) in conditions R650-50 and R650-75, respectively. Very little spherodization of the $\alpha$ laths was observed for the as-rolled conditions at both the rolling temperatures and reduction ratios. Another important observation during rolling of the alloy at $650{ }^{\circ} \mathrm{C}$ is the occurrence of deformation twinning in conditions R650-50 and R650-75, see inset of Figs. 5(a) and (b). The morphology of the twins is mostly lenticular in shape. The average volume fraction of twins, $V_{T}$, in R650-50 and R650-75 are $14.8 \pm 1.2 \%$ and $17.3 \pm 1.7 \%$, respectively. To determine the active twin mode in Ti407 rolled at $650{ }^{\circ} \mathrm{C}$, EBSD analysis was performed on one of the R650-75 sample (Fig. 6). Active twin mode was identified based on the unique misorientation axis/angle between the twin relative to the parent matrix [30]. Line profile of point-topoint misorientation angle along the arrow in Fig. 6 indicates that the axis of misorientation is $<11 \overline{2} 0>$ and the angle between the twin and the parent matrix is $85^{\circ}$, confirming it to be $\{10 \overline{1} 2\}$ tensile twin [31-33]. Detailed microstructural analysis indicates no evidence of any tensile or compressive twinning mode in samples rolled at $820^{\circ} \mathrm{C}$.

The microstructures of the annealed conditions are shown in Fig. 7. As evident from those micrographs only RA650-75 (Fig. 7b) showed strong evidence of spherodization of the $\alpha_{\mathrm{p}}$ laths and $\beta$ grains which subsequently transforms to globular $\alpha_{\mathrm{s}}$ during cooling to room temperature. Microstructures of the other conditions were characterized by high aspect ratio of $\alpha$ laths with occasional bending or kinking. It is important to mention that relative high temperature of annealing $\left(820^{\circ} \mathrm{C}\right)$ post rolling at $650{ }^{\circ} \mathrm{C}$ makes it difficult to quantify twinning activity in RA650-50 and RA650-75 conditions.

\subsection{Quantification of spherodization}

In the present work, process of static spherodization involves annealing of the rolled samples at $820{ }^{\circ} \mathrm{C}$ for $8 \mathrm{~h}$, at which, according to Fig. 2, around $50 \% \beta$-phase is present. To distinguish between $\alpha_{\mathrm{p}}$ and $\alpha_{\mathrm{s}}$ laths after annealing, quantification of 
spherodization were performed on samples water-quenched from the annealing temperature resulting in $\beta$-phase transforming martensitically.

Fig. 8(a) shows the content of $\alpha_{p}$ laths spherodized in annealed conditions together with optical micrographs of the water-quenched conditions and Fig. 8(b) shows histogram plots of aspect ratio. It can be seen that level of spherodization remains relatively low apart from the RA650-75 condition. It appears that the critical level of reduction required for complete spherodization of Ti407 at $650{ }^{\circ} \mathrm{C}$ lies in the range of $50-75 \%$. The variation of aspect ratio of $\alpha_{p}$ laths in Fig. 8(b) provides further insight into the spherodization behavior in annealed condition. The aspect ratio of majority of $\alpha_{\mathrm{p}}$ laths in RA650-75 condition was less than 3 indicating complete spherodization, while it was more than 4 in RA650-50, RA820-50 and RA820-75. The heterogeneous nature of deformation in the samples rolled and annealed at 820 ${ }^{\circ} \mathrm{C}$ (RA820-50 and RA820-75) in comparison to $650{ }^{\circ} \mathrm{C}$ is also evident from the skewed nature of distribution of aspect ratio of $\alpha_{\mathrm{p}}$.

\subsection{Macrotexture}

The macroscopic $\alpha$-phase textures of Ti407 in as-rolled and annealed conditions are shown in Figs. 9 and 10 respectively, using $\{0002\}$ and $\{10 \overline{1} 0\}$ PFs. In the as-rolled condition, Fig 9, the R650-50 and R650-75 conditions develop typical B/N texture components with the $<\mathrm{c}>$-axis orientated in the ND with up to a $30^{\circ}$ tilt towards the TD. The intensity of this texture component increases with increasing reduction ratio. The R650-50 condition also showed a slight TD (0002) texture component (Fig. 9a). In contrast, the R820-50 and R820-75 conditions only display a weak TD texture component. Compared to as-rolled condition, in annealed condition (Fig. 10), marginal strengthening of pre-existing $\mathrm{B} / \mathrm{N}$ texture component was observed in RA650-50 while the intensity of TD texture component remains unchanged. In RA650-75 condition, the intensity of B/N texture component decreases slightly. In RA820-50 and RA820-75 conditions, annealing does not result in strengthening of

TD texture component.

\subsection{Microtexture}

\subsubsection{Misorientation distribution}


Before presenting the microtexture maps, it is instructive to study the evolution of misorientation distribution at different rolling reductions in as-rolled and annealed conditions. The misorientation profiles (MPs) in different conditions are shown in Figs. 11(a)-(c) including the homogenized condition for comparison. As expected, the homogenized condition showed several characteristic misorientation peaks related to the BOR between neighboring $\alpha$ variants within the same prior $\beta$ grain [34-38]. The height and sharpness of the $\beta \rightarrow \alpha$ phase transformation peaks decreases with rolling reduction, indicating deviation from the BOR. A significant increase in the intensity of the baseline profile was observed in rolled and annealed conditions, showing increase in the number of random angle grain boundaries. In the as-rolled condition, the intensity of the $\beta \rightarrow \alpha$ phase transformation peaks in conditions R820-50 and R82075 was higher in comparison to R650-50 and R650-75. Surprisingly, the intensity of the $85^{\circ} /<11 \overline{2} 0>$ misorientation peak due to $\{10 \overline{1} 2\}$ tensile twins $[39,40]$ are quite small and similar to the intensity of random high-angle grain boundaries in the R65050 and R650-75 conditions. For the annealed conditions, the intensity of $\beta \rightarrow \alpha$ phase transformation peaks was significantly higher for RA820-75 in comparison to other conditions.

\subsubsection{Microtexture maps}

Grain boundary misorientation (GBM) (a and d) and grain orientation maps (b and e) in inverse pole figure (IPF) color code of R650-75 and R820-50 are shown in Fig. 12 and the corresponding annealed conditions can be seen in Fig. 13. In addition, $\{0002\}$ $\alpha$ phase PFs based on the IPF color code are used (c and $f$ ) to represent the texture in these selected regions. In the GBM map boundaries with misorientation 10, 60 and $90^{\circ}$ are shown in red, green and yellow color, respectively. Due to absence of twinning activity at $820{ }^{\circ} \mathrm{C}, 85^{\circ} /<11 \overline{2} 0>$ tensile twin boundaries are shown in blue color only in samples rolled at $650{ }^{\circ} \mathrm{C}$. Here the microtexture results are presented only for those conditions where significant differences in IPF and texture are observed.

\section{R650-75}

Rolling Ti407 at $650{ }^{\circ} \mathrm{C}$ to $75 \%$ reduction in thickness produces locally a very sharp microtexture, see Fig. 12 ( $b$ and $c$ ). The $\alpha / \beta$ lamellar structure is partially broken 
down with formation of fine equiaxed $\alpha$ grains. Interestingly, distinct patches of red color or macrozones with sizes in the range of 100-250 $\mu \mathrm{m}$ are observed. These red patches have features similar to $\alpha$ colonies and display an elongated shape with alignment towards RD. Fig. 12 ( $b$ and c) also reveals that the deformed $\alpha$ colonies exhibit very few different orientations. The $\{0002\} \alpha$-phase PF shows that most of the red color orientations in the IPF map are within $\pm 30^{\circ}$ from ND while green orientations mainly contributing to TD texture component (Fig. 12c). The observed $\{0002\} \alpha$-phase microtexture PF closely resembles the macrotexture PF (Fig. 9b). It is also interesting to note that the TD texture component, which was absent in the macrotexture PF (see Fig. 9b), is present in the microtexture PF. As seen from Fig. 12(c), $\beta$ variant ( $\beta \rightarrow \alpha$ phase transformation texture components) were limited as Ti407 was rolled in $\alpha$-dominated phase. The GBM map indicates significant increase in the fraction of $10^{\circ}$ misorientation boundaries, which accounts for $10^{\circ}$ misorientation peak in Fig. 11(b). Small fraction of broken and irregular network of $85^{\circ} /<11 \overline{2} 0>$ tensile twin boundaries are also observed in Fig. 12(a).

R820-50

The GBM map, IPF and $\{0002\} \alpha$-phase PF in R820-50 condition are shown in Figs. 12 (d) to (f), respectively. Figs. 12 (d) and (e) clearly shows that the microstructure is composed of long and slender $\alpha$ laths with different crystallographic orientation. The observed morphology correlates very well with the optical micrograph in Fig. 5(c). The IPF map shows patches of specific orientations with the size and features similar to $\alpha_{s}$, formed from the $\beta \rightarrow \alpha_{s}$ phase transformation at the end of the rolling temperature procedure. The uniformity of color within a given patch supports that $\alpha_{s}$ laths have the same orientation. The pink and green orientation in the IPF map corresponds to 10 and $60^{\circ}$ while yellow orientation (almost none are seen in the map here) corresponds to $90^{\circ}$ misorientation boundaries in the GBM map. The fraction of 10 and $60^{\circ}$ misorientation boundaries are very high in comparison to $90^{\circ}$. Thus, presence of 10 , 60 and $90^{\circ}$ misorientation boundaries in GBM map of R820-50 indicates little spherodization with retention of BOR between $\beta$ and $\alpha$.

It is interesting to note that $\alpha$ laths of different variants contribute to different texture components (Fig. 12f). The green orientation in the IPF contributes to TD and $\mathrm{RD}$ texture components while the blue orientation in the IPF map contribute to RD 
and other $\beta$ variant texture components. Very small fraction of red orientation in the IPF map is oriented very close to ND. Pink orientation in the IPF map contributes to RNT- $45^{\circ}$ texture components; the RNT- $45^{\circ}$ is the combination of four basal poles located $\sim 45^{\circ}$ away from RD, TD and ND. The $\{0002\} \alpha$-phase macrotexture PF components (Fig. 9c) resemble the microtexture components, although the intensity of

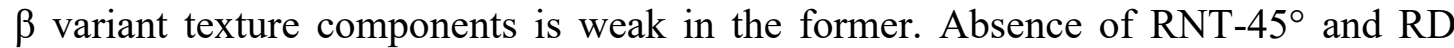
texture components in the macrotexture map (Fig. 9c) could be due to small area scanned and/or heterogeneity present in the material used to generate the microtexture map.

\section{RA650-75}

Rolling Ti407 to $75 \%$ reduction at $650{ }^{\circ} \mathrm{C}$ followed by subsequent annealing at 820 ${ }^{\circ} \mathrm{C}$ for $8 \mathrm{~h}$ resulted in microtexture similar to R650-75 condition, see Figs. 13(b) and 12(b). No additional texture component was observed as a result of annealing (Fig. $13 \mathrm{c}$ ). The spherodized red color orientations in the IPF map are oriented $\pm 30^{\circ}$ from ND towards RD and TD (Fig. 13c). Other orientation like pink and blue contributes to TD texture component. This TD texture component was absent in the $\{0002\} \alpha$-phase macrotexture PF (Fig. 10b). Similar to the R650-75 condition, extensive formation of red patches with alignment towards RD occurred in RA650-75 condition. Interrupted twin boundaries are still visible and are identified by blue color in the GBM map (Fig. 13a). The fraction of $10^{\circ}$ misorientation boundaries were marginally higher in the RA650-75 condition in comparison to R650. This is further confirmed by the height of the $10^{\circ}$ misorientation peak in Fig. 11(b) and (c).

\section{RA820-50}

After $50 \%$ reduction at $820{ }^{\circ} \mathrm{C}$ and annealing at $820{ }^{\circ} \mathrm{C}$ for $8 \mathrm{~h}$, no significant change in microtexture is observed, as it can be seen from Figs. 13(e) and (f). Distinct patches of pink and green color are less visible with development of gradient in color within it. After annealing, $\{0002\} \alpha$-phase PF becomes sharp with decrease in the spread of different texture components. Very little spherodization of red orientation in the IPF map occurred, which lies very close to ND. Other orientations like blue, pink and green maintains their lamellar morphology and contributes to $\beta$ variant, TD and RD texture components. The fraction of 10 and $60^{\circ}$ misorientation boundaries was high in comparison to $90^{\circ}$ boundaries (Fig. 13d). 


\section{$3.6 \beta$-reconstruction maps in annealed condition}

It is expected that departure from the BOR between $\alpha$ colony variants within an original $\beta$ grain during deformation will indicate spherodization of $\alpha$ laths. $\beta$ reconstruction maps are therefore useful in accessing the effect of reduction ratio and temperature on $\alpha$ lath break-up. In order to confirm this, $\beta$-reconstruction maps on large cross-sectional areas were constructed and are shown in Fig. 14. The extent of $\beta$ reconstruction was 10, 7, 18.7 and $47.5 \%$ in conditions RA650-50, RA650-75, RA820-50 and RA820-75, respectively. It can be seen that the extent of $\beta$ reconstruction was higher when the material was rolled at $820^{\circ} \mathrm{C}$ in comparison to material rolled at $650{ }^{\circ} \mathrm{C}$. This is consistent with the higher degree of spherodization when material was rolled at $650{ }^{\circ} \mathrm{C}$ as the $\mathrm{BOR}$ between the $\alpha$ and $\beta$ phase is expected to be lost. On the other hand, higher degree of $\beta$-reconstruction when Ti407 is rolled at $820{ }^{\circ} \mathrm{C}$ might be due to higher amount of transformed $\beta$ product when cooling from the rolling temperature. The surprisingly higher $\beta$-reconstruction in RA820-75 condition in comparison to RA820-50 despite identical $\beta$ content ( $\sim 50 \%$ at $820^{\circ} \mathrm{C}$ ) might be due to higher stored energy prior to annealing in the former. This could have resulted in higher driving force for the nucleation and growth of $\alpha_{\mathrm{s}}$ during cooling from the annealing temperature $820{ }^{\circ} \mathrm{C}$ resulting in more $\alpha_{s}$ obeying BOR between $\beta / \alpha_{\text {s. }}$.

\section{Discussion}

\subsection{Texture evolution}

The evolution of texture in two-phase titanium alloys is strongly dependent upon the morphology and the volume fraction of the $\alpha$ and $\beta$ phases. Since the volume fraction of $\beta$ phase varies with the rolling temperature (Fig. 2), two critical temperature regimes were identified for Ti407: (1) At low rolling temperature of $650{ }^{\circ} \mathrm{C}$, where the volume fraction of $\beta$ phase is small and texture can be considered to be dominated by the rolling texture of the $\alpha$ phase. (2) At the rolling temperature of $820^{\circ} \mathrm{C}$, where texture is dominated by the rolling texture of $\beta$ phase and its subsequent transformation texture component. The development of texture in these two regimes are discussed separately below:

\subsubsection{Rolling texture at $650^{\circ} \mathrm{C}$}


At this rolling temperature, $\mathrm{TD}$ and $\mathrm{B} / \mathrm{N}$ texture components appeared when rolled to $50 \%$ reduction in thickness with the TD texture component vanishing and the strength of the $\mathrm{B} / \mathrm{N}$ component increasing when reduction ratio is increased to $75 \%$. The presence of TD texture component in the material rolled to $50 \%$ reduction is quite surprising and is not a texture component that would be predicted by plasticity modeling [41]. Hence, it is more likely a component retained from the starting condition. As mentioned earlier, the starting homogenized condition is weakly textured with three weak components, including one towards TD. Hence, this texture component appears to be relatively stable during uniaxial rolling in the low temperature regime.

The $\mathrm{B} / \mathrm{N}$ texture component is consistent with the deformation texture of Ti6Al-4V at low temperatures [13,39,42-45]. For instance, Salem et al. [45] observed $\mathrm{B} / \mathrm{N}$ texture component in Ti-6Al-4V alloy unidirectionally rolled at $815{ }^{\circ} \mathrm{C}$ to $33 \%$ reduction in thickness. Note that relative to the $T_{\beta}$, rolling Ti407 at $650{ }^{\circ} \mathrm{C}$ is approximately equivalent to rolling Ti-6Al-4V at $815^{\circ} \mathrm{C}$. Moreover, this B/N texture component also develops during cold rolling of CP-Ti [46] and $\mathrm{Zr}$ alloy [47]. In these materials, deformation twinning is considered as the main reason for the development of $\mathrm{B} / \mathrm{N}$ texture component. More recently, Prakash et al. [39] linked this texture component to deformation twinning also in Ti-6Al-4V, which is further supported in [48] where experimentally determined cold rolling texture of Ti-6Al-4V could only be predicted by Taylor theory modelling when deformation through $\{10 \overline{1} 2\}$ tensile twinning mode was considered. In the present work, considering the similarity of the $\alpha$-phase (very low $\mathrm{Al}$ content) to $\mathrm{CP}-\mathrm{Ti}$, and the evidence of twinning provided in Figs. 5 (a) and (b), it seems clear that the main reason for the development of $\mathrm{B} / \mathrm{N}$ texture component in Ti407 alloy rolled at $650{ }^{\circ} \mathrm{C}$ is due to activation of $\{10 \overline{1} 2\}$ tensile twinning mode, which provides an $85^{\circ}$ rotation of the $<c>$-axis towards the compressive stress direction, i.e. ND. It should be noted that dramatic texture changes resulting in a strong $\mathrm{B} / \mathrm{N}$ texture cannot be accomplished by basal or prismatic $<a>$ slip induced grain rotation.

\subsubsection{Rolling texture at $820^{\circ} \mathrm{C}$}

The observed TD texture component in the specimens rolled at $820{ }^{\circ} \mathrm{C}$ to 50 and $75 \%$ reduction in thickness is consistent with the rolling texture of Ti-6Al-4V rolled high 
in the $\beta$ phase field $[44,45,49]$. When compared with the starting texture components in the homogenized condition, any indication of a texture component near RD vanished whereas the strength of TD texture component increases marginally with increasing reduction ratios. The absence of RD texture component has been observed previously in Ti-6Al-4V rolled at $925^{\circ} \mathrm{C}$ at a relatively low deformation levels with starting TD, RD and RNT- $45^{\circ}$ texture components [49]. This observation was explained on the basis of kinking and bending of $\alpha$ lamellae at low strain levels [49]. It is well known that in titanium alloys shearing/kinking occurs in hard oriented $\alpha$ laths that are very difficult to deform [7-9]. Shearing/kinking could explain disappearance of RNT- $45^{\circ}$ texture component in the present case, however, disappearance of RD texture component cannot be caused by shearing/kinking.

As mentioned above at higher rolling temperature of $820{ }^{\circ} \mathrm{C}$, where deformation is dominated by the $\beta$ phase, the final $\alpha$ phase texture evolve as a result of deformation texture of the $\beta$ phase and its subsequent $\beta \rightarrow \alpha$ phase transformation texture according to BOR. The TD texture component observed in the material rolled at $820^{\circ} \mathrm{C}$ might have evolved to some extend from the TD component present in the starting homogenized condition. However, several other sources of TD texture component have been reported in the literature for $\alpha+\beta$ Ti alloys like Ti-6Al-4V rolled in the $\beta$ rich field $[42-44,49,50]$. The formation of the TD texture component was rationalized more recently in terms of deformation texture of the $\beta$ phase and its subsequent transformation to $\alpha$ phase during cooling with variant selection $[43,44]$. According to the BOR, $\alpha$ phase forms on one of the 6 possible $\{110\}$ planes of the $\beta$ phase. In line with it, Obasi et al. [44] found that increased fraction of $\beta$ texture component $<111>/ / \mathrm{ND} \gamma$ fibre in Ti-6Al-4V rolled at $950{ }^{\circ} \mathrm{C}$ increases the propensity of $\beta$ grain pairs with closely aligned (110) planes and thus results in stronger variant selection.

\subsection{Spherodization behavior}

Ti407 blanks rolled at 650 and $820{ }^{\circ} \mathrm{C}$ where subjected to an annealing treatment at $820{ }^{\circ} \mathrm{C}$ for $8 \mathrm{~h}$ to promote static spherodization. Due to very short preheat time $(\sim 3$ min) between consecutive steps during rolling, it is likely that the fraction of metadynamically spherodized $\alpha$ laths is small enough to be neglected [8]. The driving force for static spherodization depends upon stored energy during deformation, which in turn, depends on the extent of deformation and the deformation temperature 
$[18,19,51,52]$. Other factors like the cooling rate after rolling and the annealing temperature and time are similar in conditions RA650-50, RA650-75, RA820-50 and RA820-75; thus, its influence on static spherodization kinetics can be expected to be similar. The stored energy during deformation, $E_{D}$, is given by [51]:

$$
E_{D}=\frac{1}{2} \rho G b^{2}
$$

where $\rho$ is the dislocation density, $G$ is the shear modulus and $b$ is the Burgers vector. $E_{D}$ should increase in the order R820-50 $<\mathrm{R} 820-75<\mathrm{R} 650-50<\mathrm{R} 650-75$ because lower recovery rate and higher dislocation densities gives rise to higher driving force for recrystallization when Ti407 is rolled at lower temperature, $650{ }^{\circ} \mathrm{C}$. To further ascertain this, qualitative estimation of stored energy at the two extremum in as-rolled condition (R650-75 and R820-50) were analysed through KAM technique (Fig. 15). The more whitish regions in condition R650-75 compared to R820-50 indicate a higher stored energy for complete spherodization. Fig. 15(b) also displays heterogeneous distribution of stored energy within $\alpha$ colonies in the case of R820-50.

Fig. 8(a) indicates that the content of $\alpha_{\mathrm{p}}$ laths spherodized in annealed conditions RA820-50 and RA820-75 were smaller in comparison to RA650-50 and RA650-75. The occurrence of deformation twinning in the material rolled at $650{ }^{\circ} \mathrm{C}$ (as confirmed by microstructural analysis and reorientation of grains from TD to $\mathrm{B} / \mathrm{N}$ orientation) along with higher stored energy might suggest that these two factors promoted static spherodization of R650-50 and R650-75 during annealing at $820{ }^{\circ} \mathrm{C}$. The formation of deformation twins during rolling subdivides the $\alpha$ lath by forming twin boundaries and consequently reduces the aspect ratio of $\alpha$. In addition to higher stored energy, these subdivided $\alpha$ lamellae by twin boundaries spherodizes according to boundary splitting and termination migration/Ostwald ripening mechanism [1619,26,53]. The $V_{T}$ of twins increases with increasing rolling reduction from 50 to $75 \%$ in condition R650-75. This explains higher degree of spherodization in R650-75 condition in comparison to R650-50. Chun et al. [46] found that twinning becomes saturated at a later stage of deformation in titanium. Additional spherodization of $\alpha$ laths at a later stage of deformation could have occurred by sub-grain formation through dislocation slips and its subsequent coarsening to minimize interface energy [16-19,26,53]. In contrast, when Ti407 was rolled at $820{ }^{\circ} \mathrm{C}$ far more limited spherodization was observed that is likely related to absence of twinning activity and 
lower stored energy prior to annealing. This was also confirmed through $\beta$ reconstruction maps in conditions RA820-50 and RA820-75 where $\alpha$ laths maintained BOR with $\beta$.

\subsection{Comparison of static spherodization kinetics with Ti-6Al-4V}

Static spherodization behavior of Ti407 in conditions RA650-75 and RA820-75 are compared with the most commonly used $\alpha+\beta$ titanium alloy, Ti-6Al-4V rolled to $75 \%$ reduction at 800 and $950{ }^{\circ} \mathrm{C}$ followed by subsequent annealing at $950{ }^{\circ} \mathrm{C}$ for $8 \mathrm{~h}$ [44]. These conditions are selected because relative to the $T_{\beta}$ and in terms of the $V_{\beta}$, rolling Ti407 at temperatures 650 and $820^{\circ} \mathrm{C}$ is approximately equivalent to rolling Ti-6Al$4 \mathrm{~V}$ at 800 and $950{ }^{\circ} \mathrm{C}$, respectively. The average $V_{\beta}$ at 800 and $950{ }^{\circ} \mathrm{C}$ for Ti-6Al-4V are 15 and $70 \%$ [44] in comparison to 25 and $50 \%$ for Ti407 at 650 and $820{ }^{\circ} \mathrm{C}$. Also, the relative annealing temperature $\left(950{ }^{\circ} \mathrm{C}\right.$ in Ti-6Al-4V equivalent to $820{ }^{\circ} \mathrm{C}$ in Ti407) and annealing time $(\sim 8 \mathrm{~h})$ are similar in both cases. Fig. 16 shows the microstructures of Ti-6Al-4V and Ti407 in these conditions. Direct comparison of Figs. 16 (a) and (b) for Ti-6Al-4V [44] with Figs. 16(c) and (d) of Ti407 clearly shows complete spherodization occurred in Ti-6Al-4V at both the temperatures in contrast to only in RA650-75 condition.

Sluggish spherodization kinetics of $\alpha$ laths in RA820-50, RA820-75 and RA650-50 conditions is further investigated based on the quantitative model of static spherodization proposed by Semiatin and co-workers $[16,18,19,26]$. During static spherodization, the aspect ratio of the $\alpha$ lath decreases quickly by the boundary splitting process in the initial stage of annealing and much more gradually at a later stage of annealing through termination migration. For Ti407, aspect ratio of majority of the $\alpha$ laths are greater than $>4$ in conditions RA820-50, RA820-75 and RA650-50 (Fig. 8b), indicating boundary splitting mechanism dominated static spherodization process. Semiatin et al. used Mullins grooving analysis [54] to analyze boundary splitting. The estimated time required for the completion of boundary splitting, $t_{B S}$, is controlled by the volume diffusion penetration of $\alpha$ platelets by $\beta$ phase and is proportional to:

$$
t_{B S} \sim t_{\alpha}^{3} C_{\beta} D_{\beta}
$$


where $t_{\alpha}$ is the width of the $\alpha$ lath, $C_{\beta}$ is the concentration and $D_{\beta}$ is the diffusivity of the rate limiting solute in the $\beta$ phase. The possible reasons for the sluggish spherodization kinetics of $\alpha$ laths in Ti407 are listed below:

(1) Setting aside rolling parameters, a major difference between Ti407 and Ti-6Al-4V is the chemical composition. In comparison to Ti-6Al-4V, Ti407 contains lower Al content while $\mathrm{V}$ content remains the same. Additional elements like $\mathrm{Si}$ and $\mathrm{Fe}$ are present in Ti407, which are absent in Ti64. The diffusivity of solutes in the $\beta$ phase should follow the order $D_{V}<D_{A l}<D_{F e}<D_{S i}$ in Ti407 and $D_{V}<D_{A l}$ in Ti-6Al-4V [55]. Therefore, $\mathrm{V}$ is the rate limiting solute in the $\beta$ matrix of both Ti407 and Ti-6Al-4V. Identical $C_{\beta}$ and $D_{\beta}$ of $\mathrm{V}$ in Ti-6Al-4V and Ti407 rule this factor out.

(2) According to Eq. [2], $t_{B S}$ depends upon $t_{\alpha}$ in a cubic manner. Much finer starting structure accelerates static spherodization process through boundary splitting mechanism as it involves shorter diffusion distances. However, starting $\alpha$ lath width in Ti407 and Ti-6Al-4V [44] are identical $(\sim 10 \mu \mathrm{m})$. This hypothesis is also ruled out.

(3) Si present in titanium alloys either in the form of substitutional solute atoms or in the form of silicide precipitates locks dislocations and retards cross-slip of dislocations on parallel slip planes [56-60]. Consequently, it is conceived that subgrain boundaries formation via cross-slips of dislocations during boundary splitting process is delayed. Thus slowing down the spherodization process during annealing treatment. However, further work is needed in this direction to confirm this.

(4) In the work of Obasi et al. [44], Ti-6Al-4V is subjected to $15 \%$ reduction per pass in comparison to $5 \%$ in RA820-75 condition to achieve $75 \%$ reduction in total 5 and 27 passes, respectively. It may be possible that higher reduction per pass with relatively higher rolling temperature in Ti-6Al-4V resulted in more dynamically spherodized $\alpha$ laths prior to annealing in comparison to Ti407 rolled to $75 \%$ reduction at $820^{\circ} \mathrm{C}$.

\section{Conclusions}

The evolution of microstructure, macro and micro textures during rolling of Ti407, at two different temperatures 650 and $820{ }^{\circ} \mathrm{C}$, followed by annealing at $820{ }^{\circ} \mathrm{C} /$ air 
cooling with lamellar starting microstructure was determined. The main findings of this work are summarized below:

- Annealing Ti407 above the $T_{\beta}$ temperature in homogenized condition produces lamellar microstructure with very weak TD texture component.

- Microstructural analysis through optical metallography and EBSD reveals that when Ti407 is rolled at $650{ }^{\circ} \mathrm{C}$ twin deformation becomes important while deformation is dominated by slip when the material is rolled at $820{ }^{\circ} \mathrm{C}$. Only $\{10 \overline{1} 2\}$ tensile twinning mode was identified. Activation of twinning in Ti407 is related to its low $\mathrm{Al}$ content.

- The extent of spherodization in the alloys rolled to 50 and $75 \%$ reductions at $820{ }^{\circ} \mathrm{C}$ were smaller in comparison to the alloys rolled at $650{ }^{\circ} \mathrm{C}$. Only in condition RA650-75 where the extent of deformation was $75 \%$, complete spherodization occurred. It is believed that higher stored energy prior to annealing and activation of deformation twinning when samples were rolled at $650{ }^{\circ} \mathrm{C}$ resulted in greater spherodization of primary $\alpha_{p}$ and transformed $\beta$ in RA650-75.

- A weak TD texture component is found when Ti407 is rolled at $820^{\circ} \mathrm{C}$, which is likely to be retained from the starting condition. When rolling Ti407 at 650 ${ }^{\circ} \mathrm{C}$, the strength of TD texture component decreases while $\mathrm{B} / \mathrm{N}$ texture component becomes stronger. Further annealing of the rolled alloys at $820{ }^{\circ} \mathrm{C}$ does not resulted in any new texture component formation with no noticeable change in the strength of TD and $\mathrm{B} / \mathrm{N}$ texture components in all the conditions examined.

- It is proposed that activation of $\{10 \overline{1} 2\}$ tensile twinning mode during rolling of Ti407 at $650{ }^{\circ} \mathrm{C}$ play a major role in the formation of the $\mathrm{B} / \mathrm{N}$ texture component and may accelerate subsequent spherodization of the $\alpha$ laths.

- Comparison of micrographs from Ti407 and Ti-6Al-4V subject to the same reduction ratio and temperature (relative to the $T_{\beta}$ ) indicate sluggish spherodization kinetics in former. 


\section{Acknowledgements}

Gaurav Singh, Joao Fonseca and Michael Preuss would like to thank EPSRC for financial support through Light Alloys for Sustainable Transport $2^{\text {nd }}$ Generation (LATEST2) [EP/H020047/1] and LightForm [EP/R001715/1]. G.S would also like to thank David Strong from University of Manchester for his assistance during rolling. Michael Preuss is also particularly grateful for his EPSRC Leadership Fellowship grant [EP/I005420/1].

\section{References}

[1] S. James, Y. Kosaka, R. Thomas, P. Garratt, Timetal ${ }^{\circledR}$ 407: A Titanium Alloy to Enable Cost Reduction, In: Proceedings of the $13^{\text {th }}$ World Conference on Titanium, John Wiley \& Sons, Hoboken, NJ, USA, 2016, pp. 721-725. https://doi.org/10.1002/9781119296126.ch121

[2] J.C. Williams, R.G. Baggerly, N.E. Paton, Deformation behavior of HCP Ti-Al alloy single crystals, Metall. Mater. Trans. A. 33 (2002) 837-850. https://doi.org/10.1007/s11661-002-1016-2

[3] A. Fitzner, D.G.L. Prakash, J.Q. da Fonseca, M. Thomas, S.-Y. Zhang, J. Kelleher, P. Manuel, M. Preuss, The effect of aluminium on twinning in binary alpha-titanium, Acta Mater. 103 (2016) 341-351.

https://doi.org/10.1016/j.actamat.2015.09.048

[4] J. Jiang, A. Godfrey, W. Liu, Q. Liu, Microtexture evolution via deformation twinning and slip during compression of magnesium alloy AZ31, Mater. Sci. Eng. A. 483-484 (2008) 576-579. https://doi.org/10.1016/j.msea.2006.07.175

[5] D.J. Truax, C.J. McMahon, Plastic behavior of titanium-aluminum alloys, Mater. Sci. Eng. 13 (1974) 125-139. https://doi.org/10.1016/0025-5416(74)90181-5

[6] A. Kimura, S. Nakamura, S. Isogawa, T. Matsubara, K. Kimura, Y. Sato, A free machining titanium alloy for connecting rods, SAE Technical Paper, No. $910425,1991$.

https://doi.org/10.4271/910425

[7] G. Welsch, R. Boyer, E.W. Collings, Materials Properties Handbook: Titanium Alloys, ASM International, Materials Park, Ohio, 1993.

[8] S.L. Semiatin, V. Seetharaman, I. Weiss, The thermomechanical processing of alpha/beta titanium alloys, JOM. 49 (1997) 33-39.

https://doi.org/10.1007/BF02914711

[9] I. Weiss, S.L. Semiatin, Thermomechanical processing of alpha titanium alloys - an overview, Mater. Sci. Eng. A. 263 (1999) 243-256.

https://doi.org/10.1016/S0921-5093(98)01155-1

[10] I. Weiss, S.L. Semiatin, Thermomechanical processing of beta titanium alloys - an overview, Mater. Sci. Eng. A. 243 (1998) 46-65.

https://doi.org/10.1016/S0921-5093(97)00783-1

[11] M.R. Bache, W.J. Evans, Impact of texture on mechanical properties in an advanced titanium alloy, Mater. Sci. Eng. A. 319-321 (2001) 409-414. https://doi.org/10.1016/S0921-5093(00)02034-7

[12] M.R. Bache, W.J. Evans, B. Suddell, F.R.M. Herrouin, The effects of texture in titanium alloys for engineering components under fatigue, Int. J. Fatigue. 23 (2001) 153-159. 
https://doi.org/10.1016/S0142-1123(01)00124-4

[13] G. Lütjering, Influence of processing on microstructure and mechanical properties of $(\alpha+\beta)$ titanium alloys, Mater. Sci. Eng. A. 243 (1998) 32-45. https://doi.org/10.1016/S0921-5093(97)00778-8

[14] A.F. Wilson, V. Venkatesh, R. Pather, J.W. Brooks, S.P. Fox, The prediction of microstructure development during timetal 6-4 billet manufacture, In: Ti-2003: Proceedings of the $10^{\text {th }}$ World Conference on Titanium, Hamburg, Germany, 2003, pp. 321-328.

[15] A.A. Korshunov, F.U. Enikeev, M.I. Mazurskij, G.A. Salishchev, A. V Muravlem, P. V Chistyakov, O. V Dmitriev, The influence of high temperature loading technique on transformation of laminated structure in VT9 titanium alloy, Metally, 26 (1994) 121-126.

[16] S.L. Semiatin, N. Stefansson, R.D. Doherty, Prediction of the kinetics of static globularization of Ti-6Al-4V, Metall. Mater. Trans. A. 36 (2005) 1372-1376. https://doi.org/10.1007/s11661-005-0229-6

[17] S.L. Semiatin, V. Seetharaman, I. Weiss, Flow behavior and globularization kinetics during hot working of Ti-6Al-4V with a colony alpha microstructure, Mater. Sci. Eng. A. 263 (1999) 257-271. https://doi.org/10.1016/S0921-5093(98)01156-3

[18] N. Stefansson, S.L. Semiatin, Mechanisms of globularization of Ti-6Al-4V during static heat treatment, Metall. Mater. Trans. A. 34 (2003) 691-698. https://doi.org/10.1007/s11661-003-0103-3

[19] S. Zherebtsov, M. Murzinova, G. Salishchev, S.L. Semiatin, Spheroidization of the lamellar microstructure in Ti-6Al-4V alloy during warm deformation and annealing, Acta Mater. 59 (2011) 4138-4150. https://doi.org/10.1016/j.actamat.2011.03.037

[20] K. Muszka, M. Lopez-Pedrosa, K. Raszka, M. Thomas, W.M. Rainforth, B.P. Wynne, The Impact of Strain Reversal on Microstructure Evolution and Orientation Relationships in Ti-6Al-4V with an Initial Alpha Colony Microstructure, Metall. Mater. Trans. A. 45 (2014) 5997-6007. https://doi.org/10.1007/s11661-014-2590-9

[21] E.B. Shell, S.L. Semiatin, Effect of initial microstructure on plastic flow and dynamic globularization during hot working of Ti-6Al-4V, Metall. Mater. Trans. A. 30 (1999) 3219-3229. https://doi.org/10.1007/s11661-999-0232-4

[22] S. Mironov, M. Murzinova, S. Zherebtsov, G.A. Salishchev, S.L. Semiatin, Microstructure evolution during warm working of Ti-6Al-4V with a colony- $\alpha$ microstructure, Acta Mater. 57 (2009) 2470-2481.

https://doi.org/10.1016/j.actamat.2009.02.016

[23] J.C. Williams, M.J. Blackburn, Strength, deformation modes and fracture in titanium-aluminium alloys, Trans. ASM 62 (1969), 398-409.

[24] S. Zaefferer, A study of active deformation systems in titanium alloys: dependence on alloy composition and correlation with deformation texture, Mater. Sci. Eng. A. 344 (2003) 20-30. https://doi.org/10.1016/S0921-5093(02)00421-5

[25] J. Tiley, T. Searles, E. Lee, S. Kar, R. Banerjee, J.C. Russ, H.L. Fraser, Quantification of microstructural features in $\alpha / \beta$ titanium alloys, Mater. Sci. Eng. A. 372 (2004) 191-198.

https://doi.org/10.1016/j.msea.2003.12.008

[26] C.H. Park, J.W. Won, J.W. Park, S.L. Semiatin, C.S. Lee, Mechanisms and 
kinetics of static spheroidization of hot-worked Ti-6Al-2Sn-4Zr-2Mo-0.1Si with a lamellar microstructure, Metall. Mater. Trans. A. 43 (2012) 977-985. https://doi.org/10.1007/s11661-011-1019-y

[27] M.G. Glavicic, P.A. Kobryn, T.R. Bieler, S.L. Semiatin, An automated method to determine the orientation of the high-temperature beta phase from measured EBSD data for the low-temperature alpha-phase in Ti-6Al-4V, Mater. Sci. Eng. A. 351 (2003) 258-264. https://doi.org/10.1016/S0921-5093(02)00844-4

[28] C. Cayron, B. Artaud, L. Briottet, Reconstruction of parent grains from EBSD data, Mater. Charact. 57 (2006) 386-401.

https://doi.org/10.1016/j.matchar.2006.03.008

[29] L. Germain, N. Gey, M. Humbert, Reliability of reconstructed $\beta$-orientation maps in titanium alloys, Ultramicroscopy. 107 (2007) 1129-1135. https://doi.org/10.1016/j.ultramic.2007.01.012

[30] J.W. Christian, S. Mahajan, Deformation twinning, Prog. Mater. Sci. 39 (1995) 1-157. https://doi.org/10.1016/0079-6425(94)00007-7

[31] M.H. Yoo, J.K. Lee, Deformation twinning in hep metals and alloys, Philos. Mag. A. 63 (1991) 987-1000. https://doi.org/10.1080/01418619108213931

[32] A. Akhtar, Basal slip and twinning in $\alpha$-titanium single crystals, Metall. Trans. A 6 (1975) 1105-1113. https://doi.org/10.1007/BF02661366

[33] G. Singh, G. Bajargan, R. Datta, U. Ramamurty, Deformation and strength of Ti-6Al-4V alloyed with B at cryogenic temperatures, Mater. Sci. Eng. A 611 (2014) 45-57. https://doi.org/10.1016/j.msea.2014.05.075

[34] S.C. Wang, M. Aindow, M.J. Starink, Effect of self-accommodation on $\alpha / \alpha$ boundary populations in pure titanium, Acta Mater. 51 (2003) 2485-2503. https://doi.org/10.1016/S1359-6454(03)00035-1

[35] N. Gey, M. Humbert, E. Gautier, J.L. Béchade, Study of the $\beta \rightarrow \alpha$ variant selection for a zircaloy- 4 rod heated to the $\beta$ transus in presence or not of an axial tensile stress, J. Nucl. Mater. 328 (2004) 137-145.

https://doi.org/10.1016/j.jnucmat.2004.03.003

[36] D.G. Leo Prakash, M. Preuss, M. Dahlbäck, J. Quinta da Fonseca, Microstructure and texture evolution during thermomechanical processing of $\beta$ quenched Zr, Acta Mater. 88 (2015) 389-401. https://doi.org/10.1016/j.actamat.2014.12.033

[37] W.G. Burgers, On the process of transition of the cubic-body-centered modification into the hexagonal-close-packed modification of zirconium, Physica. 1 (1934) 561-586.

[38] N. Gey, M. Humbert, Characterization of the variant selection occurring during the $\alpha \rightarrow \beta \rightarrow \alpha$ phase transformations of a cold rolled titanium sheet, Acta Mater. 50 (2002) 277-287.

https://doi.org/10.1016/S1359-6454(01)00351-2

[39] D.G. Leo Prakash, R. Ding, R.J. Moat, I. Jones, P.J. Withers, J.Quinta da Fonseca, M. Preuss, Deformation twinning in Ti-6Al-4V during low strain rate deformation to moderate strains at room temperature, Mater. Sci. Eng. A. 527 (2010) 5734-5744. https://doi.org/10.1016/j.msea.2010.05.039

[40] S.V. Zherebtsov, G.S. Dyakonov, A.A. Salem, S.P. Malysheva, G.A. Salishchev, S.L. Semiatin, Evolution of grain and subgrain structure during cold rolling of commercial-purity titanium, Mater. Sci. Eng. A. 528 (2011) 3474-3479. https://doi.org/10.1016/j.msea.2011.01.039 
[41] M.G. Glavicic, R.L. Goetz, D.R. Barker, G. Shen, D. Furrer, A. Woodfield, S.L. Semiatin, Modeling of Texture Evolution during Hot Forging of Alpha/Beta Titanium Alloys, Metall. Mater. Trans. A. 39 (2008) 887-896. https://doi.org/10.1007/s11661-007-9376-2

[42] M. Peters, A. Gysler, G. Lütjering, H. Kimura, O. Izumi, Titanium'80 Science and Technology, In: Proceedings of the $4^{\text {th }}$ International Conference on Titanium, H. Kimura O. Izumi, Eds., Kyoto, 1980, pp. 1777-1786.

[43] D.G. Leo Prakash, P. Honniball, D. Rugg, P.J. Withers, J. Quinta Da Fonseca, M. Preuss, The effect of beta phase on microstructure and texture evolution during thermomechanical processing of alpha + beta Ti alloy, Acta Mater. 61 (2013) 3200-3213. https://doi.org/10.1016/j.actamat.2013.02.008

[44] G.C. Obasi, S. Birosca, D.G. Leo Prakash, J. Quinta Da Fonseca, M. Preuss, The influence of rolling temperature on texture evolution and variant selection during alpha to beta to alpha phase transformation in Ti-6Al-4V, Acta Mater. 60 (2012) 6013-6024. https://doi.org/10.1016/j.actamat.2012.07.025

[45] A.A. Salem, M.G. Glavicic, S.L. Semiatin, The effect of preheat temperature and inter-pass reheating on microstructure and texture evolution during hot rolling of Ti-6Al-4V, Mater. Sci. Eng. A. 496 (2008) 169-176.

https://doi.org/10.1016/j.msea.2008.05.017

[46] Y.B. Chun, S.H. Yu, S.L. Semiatin, S.K. Hwang, Effect of deformation twinning on microstructure and texture evolution during cold rolling of CPtitanium, Mater. Sci. Eng. A. 398 (2005) 209-219. https://doi.org/10.1016/j.msea.2005.03.019

[47] C.E. Ells, B.A. Cheadle, Aging and recovery in cold rolled $\mathrm{Zr}-2.5 \mathrm{wt} \% \mathrm{Nb}$ Alloy, J. Nucl. Mater. 23 (1967) 257-269. https://doi.org/10.1016/0022-3115(67)90158-4

[48] M.J. Philippe, M. Serghat, P. Van Houtte, C. Esling, Modelling of texture evolution for materials of hexagonal symmetry-II. application to zirconium and titanium $\alpha$ or near $\alpha$ alloys, Acta Metall. Mater. 43 (1995) 1619-1630. https://doi.org/10.1016/0956-7151(94)00329-G

[49] P. Ari-Gur, S.L. Semiatin, Evolution of microstructure, macrotexture and microtexture during hot rolling of Ti-6A1-4V, Mater. Sci. Eng. A. 257 (1998) $118-127$. https://doi.org/10.1016/S0921-5093(98)00829-6

[50] N. Gey, M. Humbert, M.J. Philippe, Y. Combres, Investigation of the alphaand beta- texture evolution of hot rolled Ti-64 products, Mater. Sci. Eng. A. 219 (1996) 80-88. https://doi.org/10.1016/S0921-5093(96)10388-9

[51] A. Rollett, F.J. Humphreys, G.S. Rohrer, M. Hatherly, Recrystallization and related annealing phenomena, Elsevier, New York, 2004.

[52] N. Stefansson, S.L. Semiatin, D. Eylon, The kinetics of static globularization of Ti-6Al-4V, Metall. Mater. Trans. A. 33 (2002) 3527-3534. https://doi.org/10.1007/s11661-002-0340-X

[53] X.G. Fan, H. Yang, S.L. Yan, P.F. Gao, J.H. Zhou, Mechanism and kinetics of static globularization in TA15 titanium alloy with transformed structure, J. Alloys Compd. 533 (2012) 1-8. https://doi.org/10.1016/i.jallcom.2012.03.113

[54] W.W. Mullins, Grain boundary grooving by volume diffusion, Trans. Am. Inst. 
Min. Metall. Eng. 218 (1960) 354-361.

[55] G. Lütjering, J.C. Williams, Titanium, Springer-Verlag, Berlin, 2003.

[56] K. Prasad, V.K. Varma, Serrated flow behavior in a near alpha titanium alloy IMI 834, Mater. Sci. Eng. A. 486 (2008) 158-166.

https://doi.org/10.1016/j.msea.2007.09.020

[57] N. Singh, V. Singh, Effect of temperature on tensile properties of near- $\alpha$ alloy Timetal 834, Mater. Sci. Eng. A. 485 (2008) 130-139.

https://doi.org/10.1016/j.msea.2007.07.064

[58] M.R. Winstone, R.D. Rawlings, D.R.F. West, The creep behaviour of some silicon-containing titanium alloys, J. Less Common Met. 39 (1975) 205-217. https://doi.org/10.1016/0022-5088(75)90195-2

[59] N.E. Paton, M.W. Mahoney, Creep of titanium-silicon alloys, Metall. Trans. A. 7 (1976) 1685-1694. https://doi.org/10.1007/BF02817886

[60] H. Flower, K. Lipscombe, The effect of silicon on the structure and mechanical properties of an $\alpha+\beta$ titanium alloy, J. Mater. Sci. 17 (1982) 1221-1231. https://doi.org/10.1007/BF00543544 


\section{List of Tables}

Table 1. Chemical composition of as-received Ti407 plate in wt.\%

\begin{tabular}{|c|c|c|c|c|c|c|c|}
\hline $\mathrm{Ti}$ & $\mathrm{Al}$ & $\mathrm{V}$ & $\mathrm{Si}$ & $\mathrm{O}$ & $\mathrm{N}$ & $\mathrm{C}$ & $\mathrm{Fe}$ \\
\hline Bal. & 0.8 & 3.8 & 0.2 & 0.11 & $<0.005$ & $<0.03$ & 0.08 \\
\hline
\end{tabular}

Table 2. Microstructural parameters of Ti407 in the homogenized condition. Prior $\beta$ grain size, $d, \alpha$ colony size, $c$, primary $\alpha$ lath size, $\lambda$, volume fractions of $\alpha, V_{\alpha}$, and $\beta$ phase, $V_{\beta}$

\begin{tabular}{|c|c|c|c|c|}
\hline$d(\mu \mathrm{m})$ & $c(\mu \mathrm{m})$ & $\lambda(\mu \mathrm{m})$ & $V_{\alpha}(\%)$ & $V_{\beta}(\%)$ \\
\hline $1200 \pm 400$ & $242 \pm 20$ & $10.7 \pm 3$ & $85 \pm 5$ & $15 \pm 5$ \\
\hline
\end{tabular}

Table 3. Rolling schedule of Ti407.

\begin{tabular}{|c|c|c|c|c|c|c|c|c|}
\hline $\begin{array}{l}\text { Rolling } \\
\text { temperature }\end{array}$ & $\begin{array}{l}\text { Starting } \\
(\mathrm{mm}) \\
\mathrm{L} \times \mathrm{W} \times \mathrm{t}\end{array}$ & $\begin{array}{l}\text { Roll to }(\mathrm{mm}) \\
\mathrm{L} \times \mathrm{W} \times \mathrm{t}\end{array}$ & $\begin{array}{l}\text { Reheat time } \\
\text { and } \\
\text { temperature }\end{array}$ & $\begin{array}{c}\text { \% Red. } \\
\text { each } \\
\text { pass }\end{array}$ & $\begin{array}{c}\text { Total } \\
\text { number } \\
\text { of passes }\end{array}$ & $\begin{array}{l}\text { Annealing } \\
\text { temperature } \\
\text { and time }\end{array}$ & $\begin{array}{c}\% \text { Total } \\
\text { red. }\end{array}$ & Acronyms \\
\hline \multirow{2}{*}{$650^{\circ} \mathrm{C}$} & \multirow{2}{*}{$50 \times 50 \times 40$} & $115 \times 62 \times 20$ & $3 \mathrm{~min} / 650^{\circ} \mathrm{C}$ & 3 & 22 & $820^{\circ} \mathrm{C} / 8 \mathrm{~h}$ & 50 & RA650-50 \\
\hline & & $153 \times 63 \times 10$ & $3 \mathrm{~min} / 650^{\circ} \mathrm{C}$ & 3 & 44 & $820^{\circ} \mathrm{C} / 8 \mathrm{~h}$ & 75 & RA650-75 \\
\hline \multirow{2}{*}{$820^{\circ} \mathrm{C}$} & \multirow{2}{*}{$50 \times 50 \times 40$} & $125 \times 57 \times 20$ & $3 \mathrm{~min} / 820^{\circ} \mathrm{C}$ & 5 & 16 & $820^{\circ} \mathrm{C} / 8 \mathrm{~h}$ & 50 & RA820-50 \\
\hline & & $73 \times 55 \times 10$ & $3 \mathrm{~min} / 820^{\circ} \mathrm{C}$ & 5 & 27 & $820^{\circ} \mathrm{C} / 8 \mathrm{~h}$ & 75 & RA820-75 \\
\hline
\end{tabular}




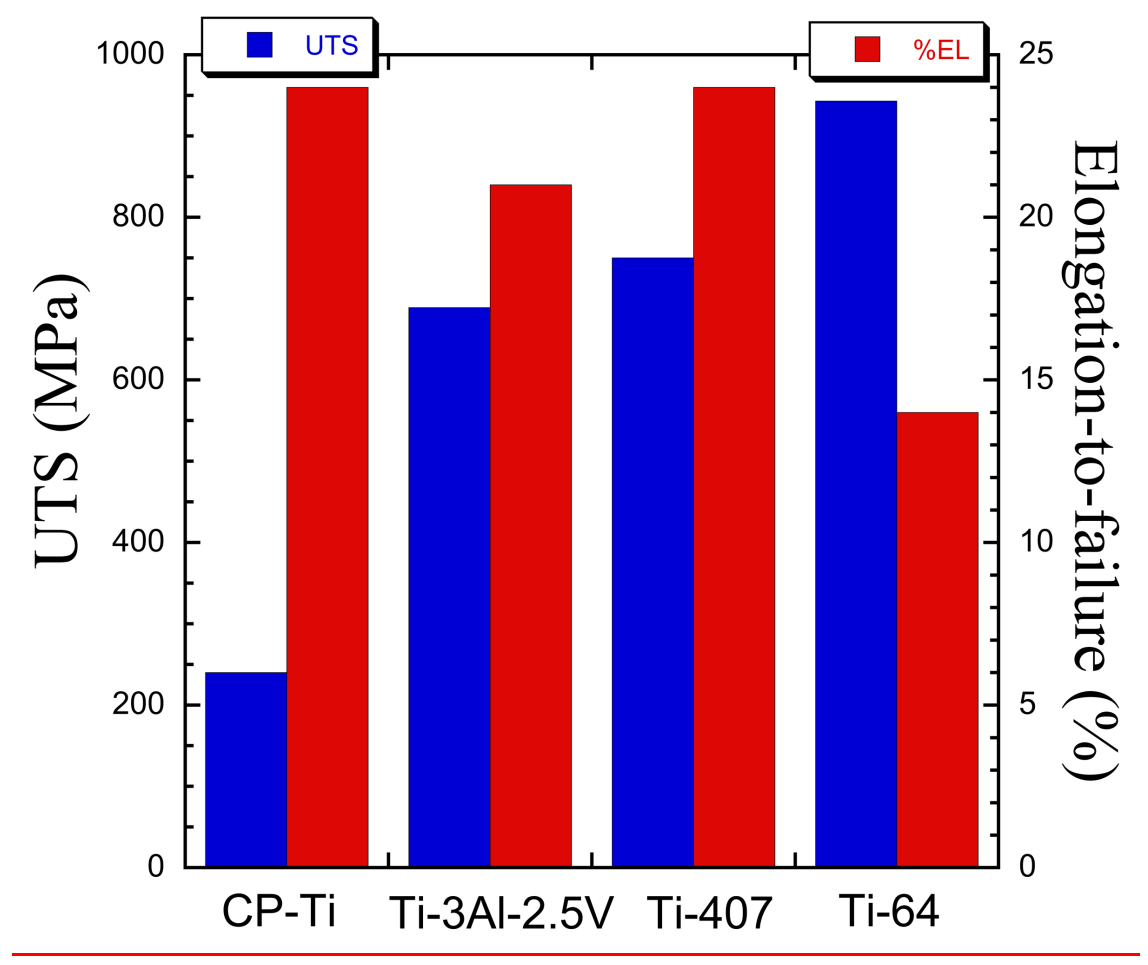

Fig. 1. Room tensile properties like ultimate tensile strength and elongation-to-failure values of some commercial titanium alloys. Note all the alloys are compared in equiaxed microstructural condition. 


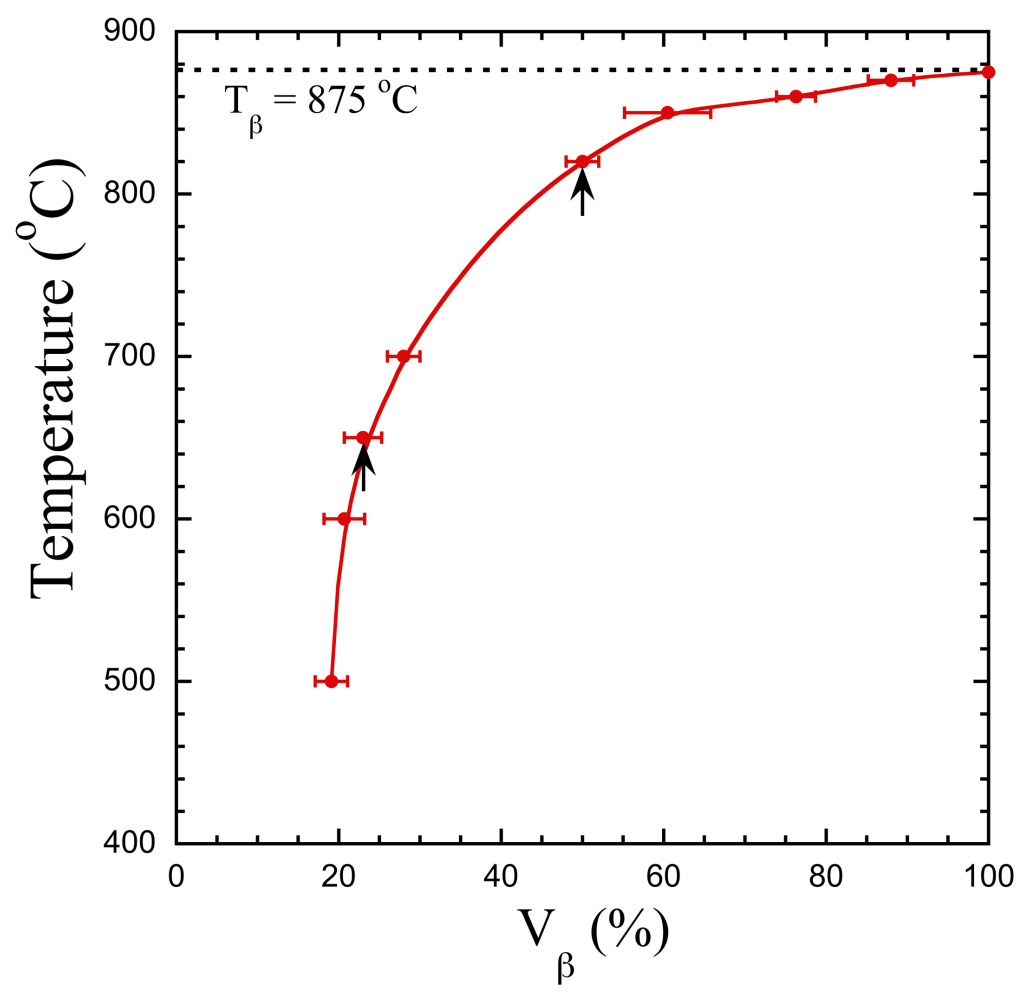

Fig. 2. Recorded $\beta$-approach curve for Ti407. Arrows indicate $\beta$-content at the two rolling temperatures of 650 and $820^{\circ} \mathrm{C}$. The $\beta$-transus temperature, $T_{\beta}$, is shown with broken line. 

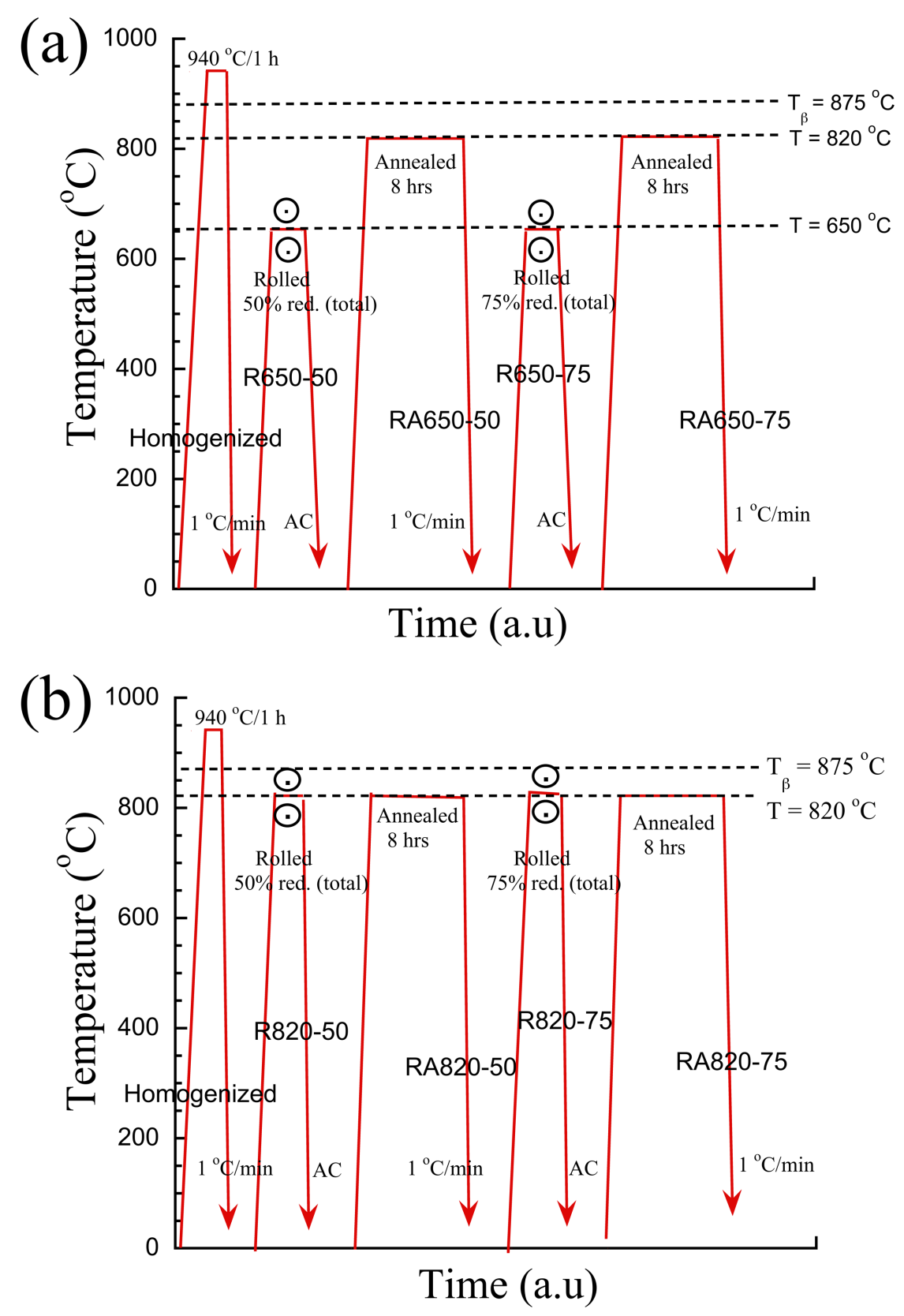

Fig. 3. Brief schematic diagrams of the rolling procedure. (a) Ti407 rolled to 50 and $75 \%$ reduction in thickness at $650{ }^{\circ} \mathrm{C}$ followed by annealing at $820{ }^{\circ} \mathrm{C}$. (b) Ti407 rolled to 50 and $75 \%$ reduction in thickness at $820{ }^{\circ} \mathrm{C}$ followed by annealing at 820 ${ }^{\circ} \mathrm{C}$. 

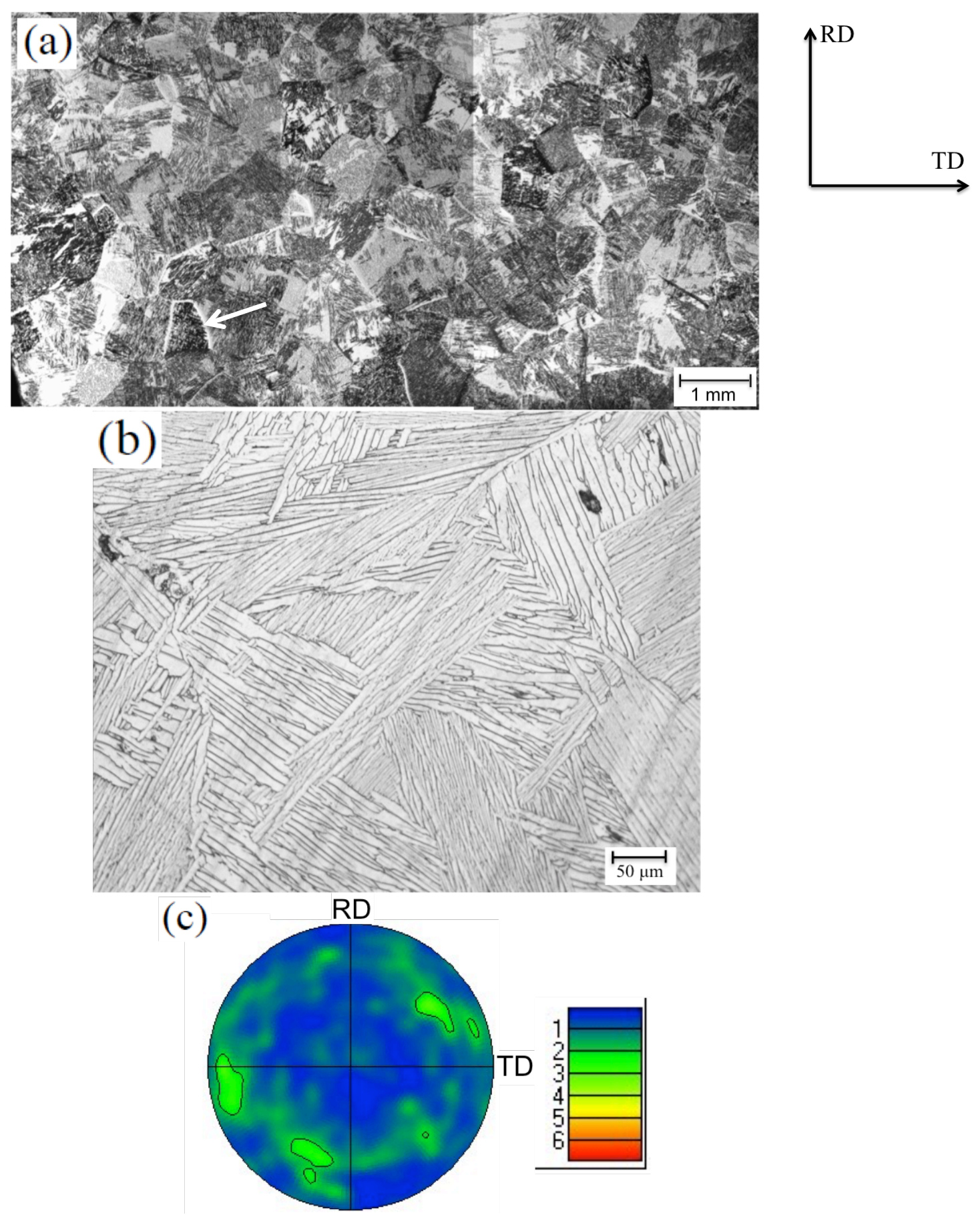

Fig. 4. (a) Low and (b) high magnification images, and (c) $\{0002\} \alpha$-phase pole figure of Ti407 plate in homogenized condition. 

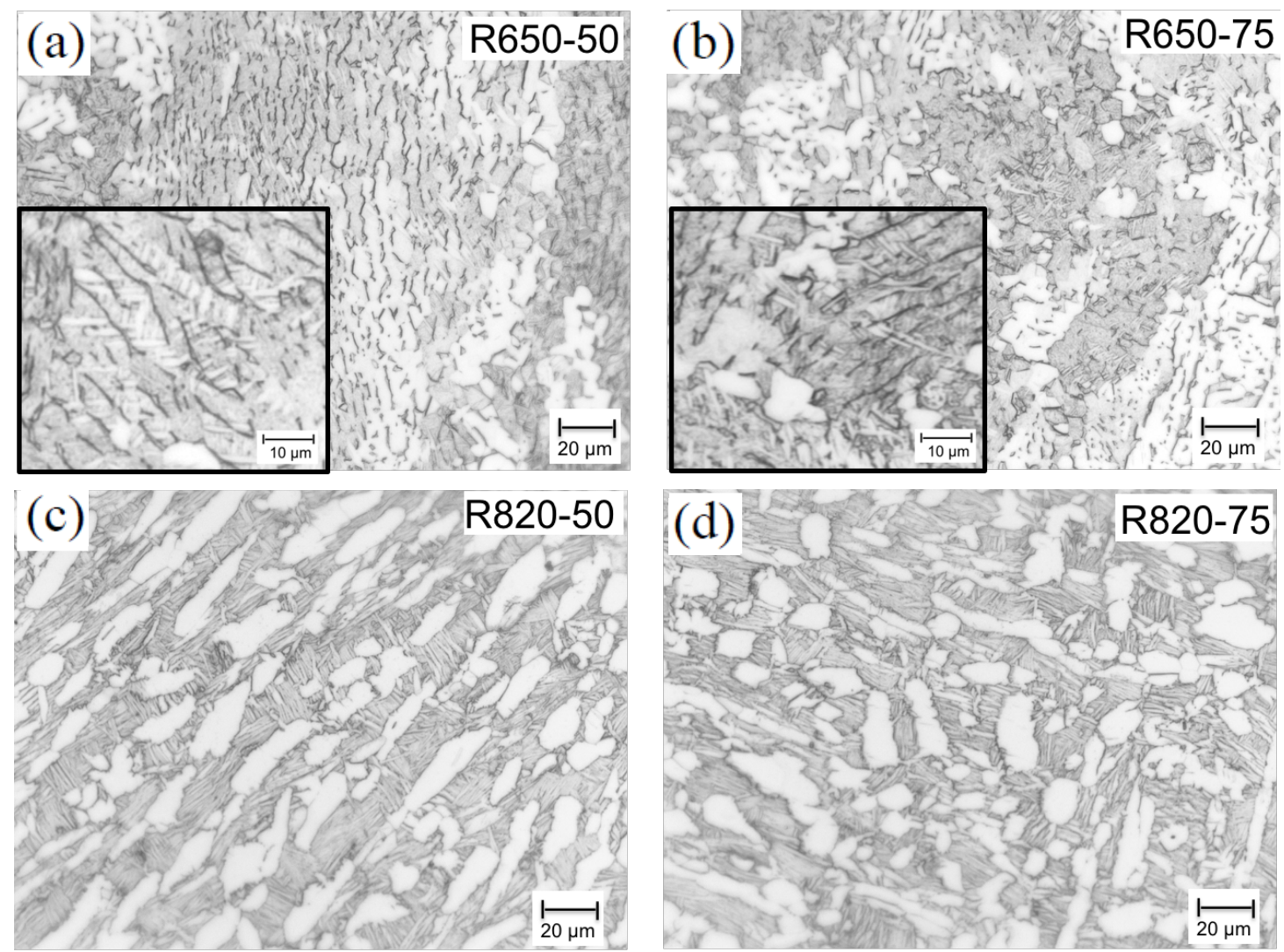

Fig. 5. Optical micrographs of Ti407 in as-rolled conditions. (a) 50 and (b) 75\% rolled at $650{ }^{\circ} \mathrm{C}$, (c) 50 and (d) $75 \%$ rolled at $820{ }^{\circ} \mathrm{C}$. Activation of deformation twins in conditions R650-50 and R650-75 are shown in the inset of (a) and (b). 

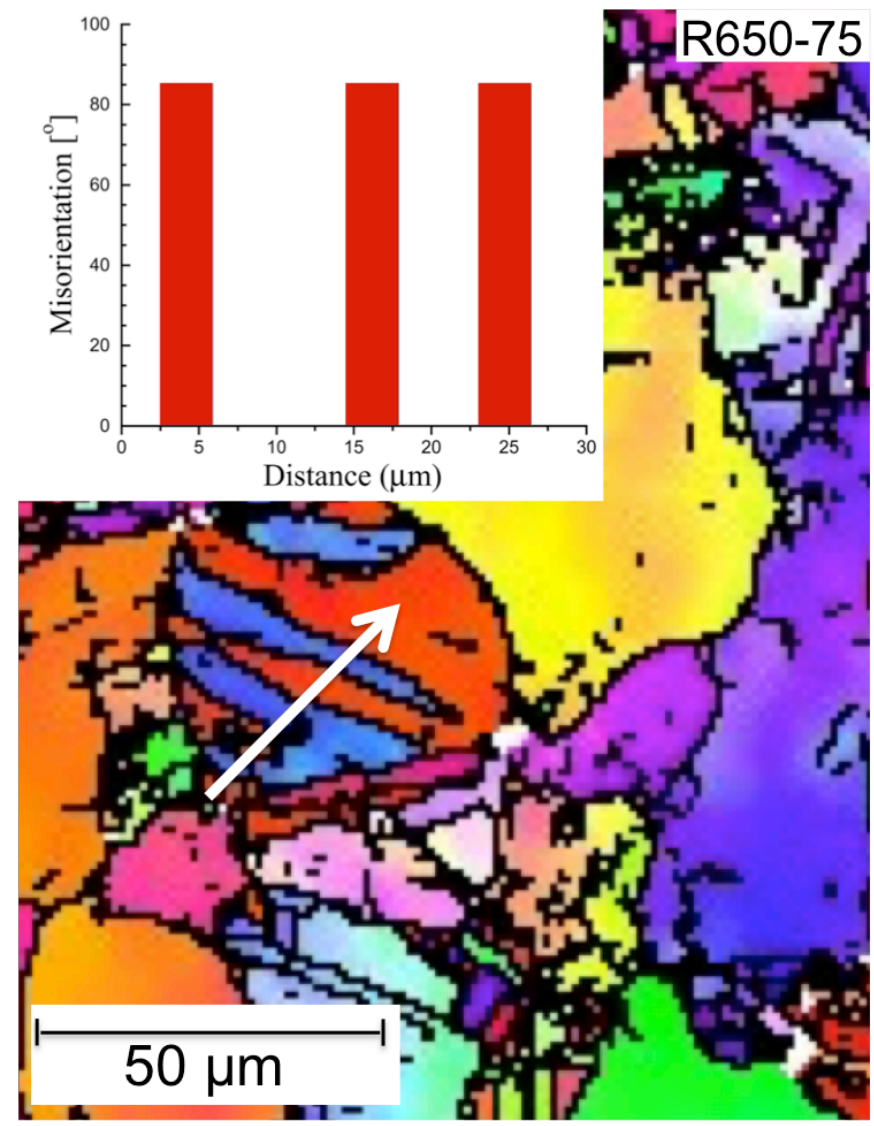

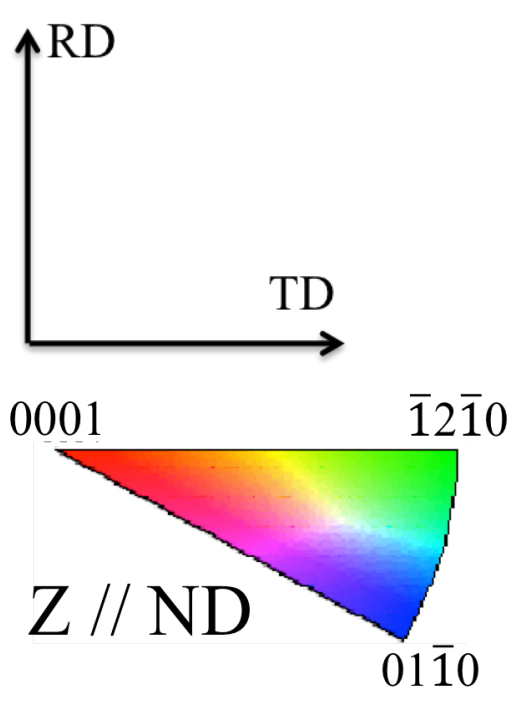

Fig. 6. Inverse pole figure (IPF) map of Ti407 rolled to $75 \%$ reduction at $650{ }^{\circ} \mathrm{C}$, R650-75 condition. White arrow in the figure indicate $\{10 \overline{1} 2\}$ twin band. Line profile of the point-to-point misorientation along the arrow is shown in the inset. The (hkl) orientation code of $\alpha$ is shown on the right side of the figure, corresponding to all the IPF maps shown in this paper (For interpretation of the references to color in this figure legend, the reader is referred to the web version of this article). 

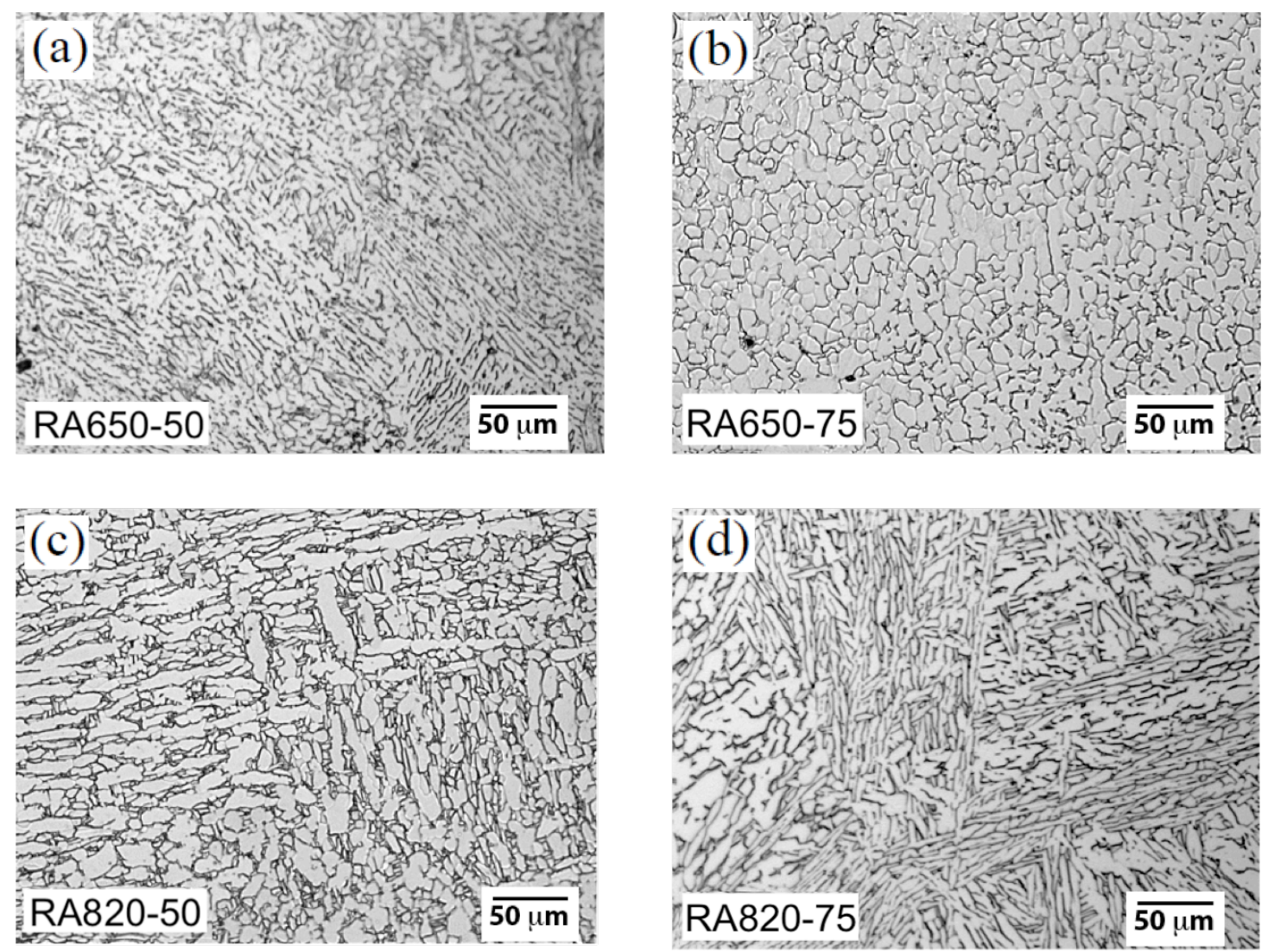

Fig. 7. Optical micrographs of Ti407 in annealed conditions. (a) 50 and (b) $75 \%$ rolled at $650{ }^{\circ} \mathrm{C}$ and annealed at $820{ }^{\circ} \mathrm{C}$ for $8 \mathrm{~h}$, (c) 50 and (d) $75 \%$ rolled at $820{ }^{\circ} \mathrm{C}$ and annealed at $820{ }^{\circ} \mathrm{C}$ for $8 \mathrm{~h}$. 
(a)

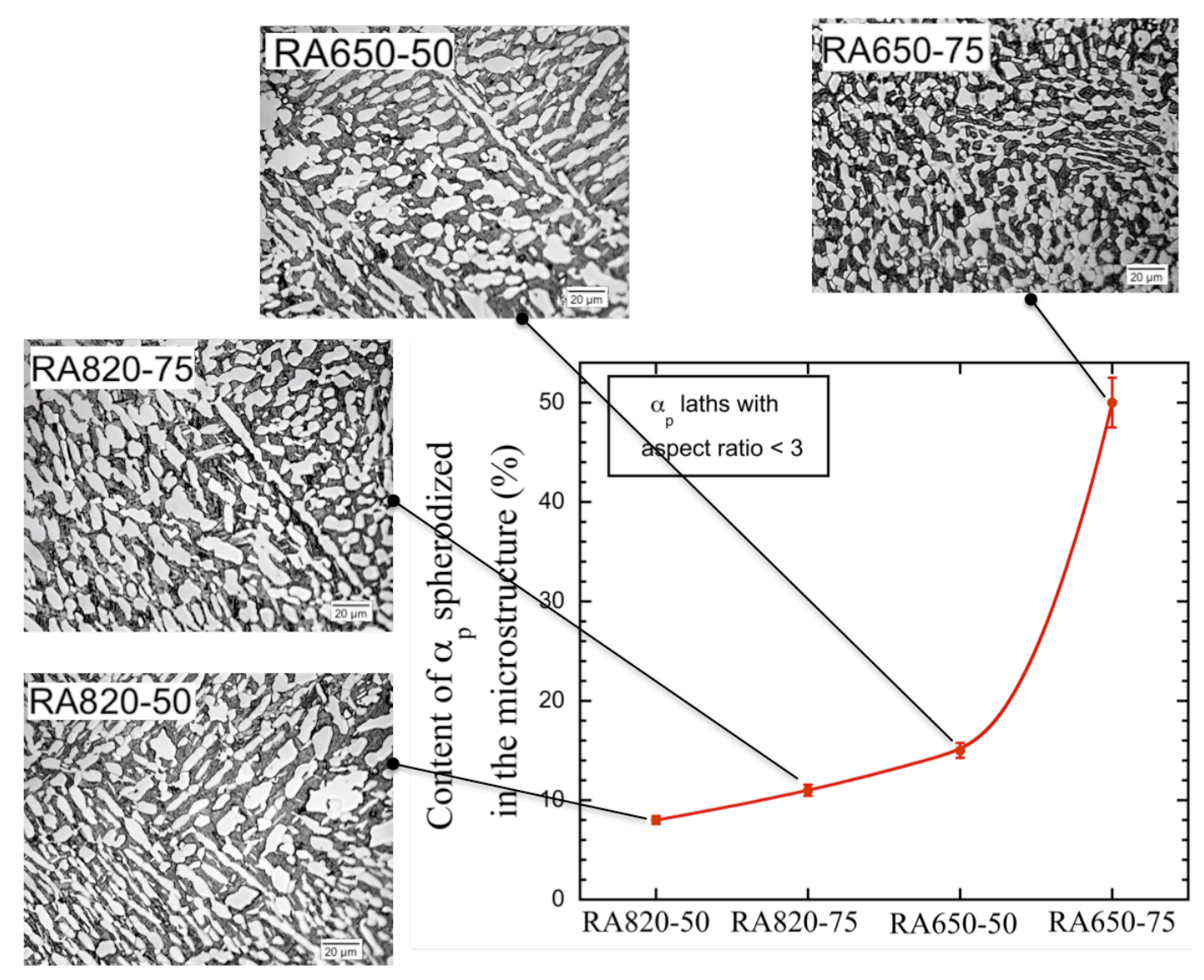

Continued 
(b)
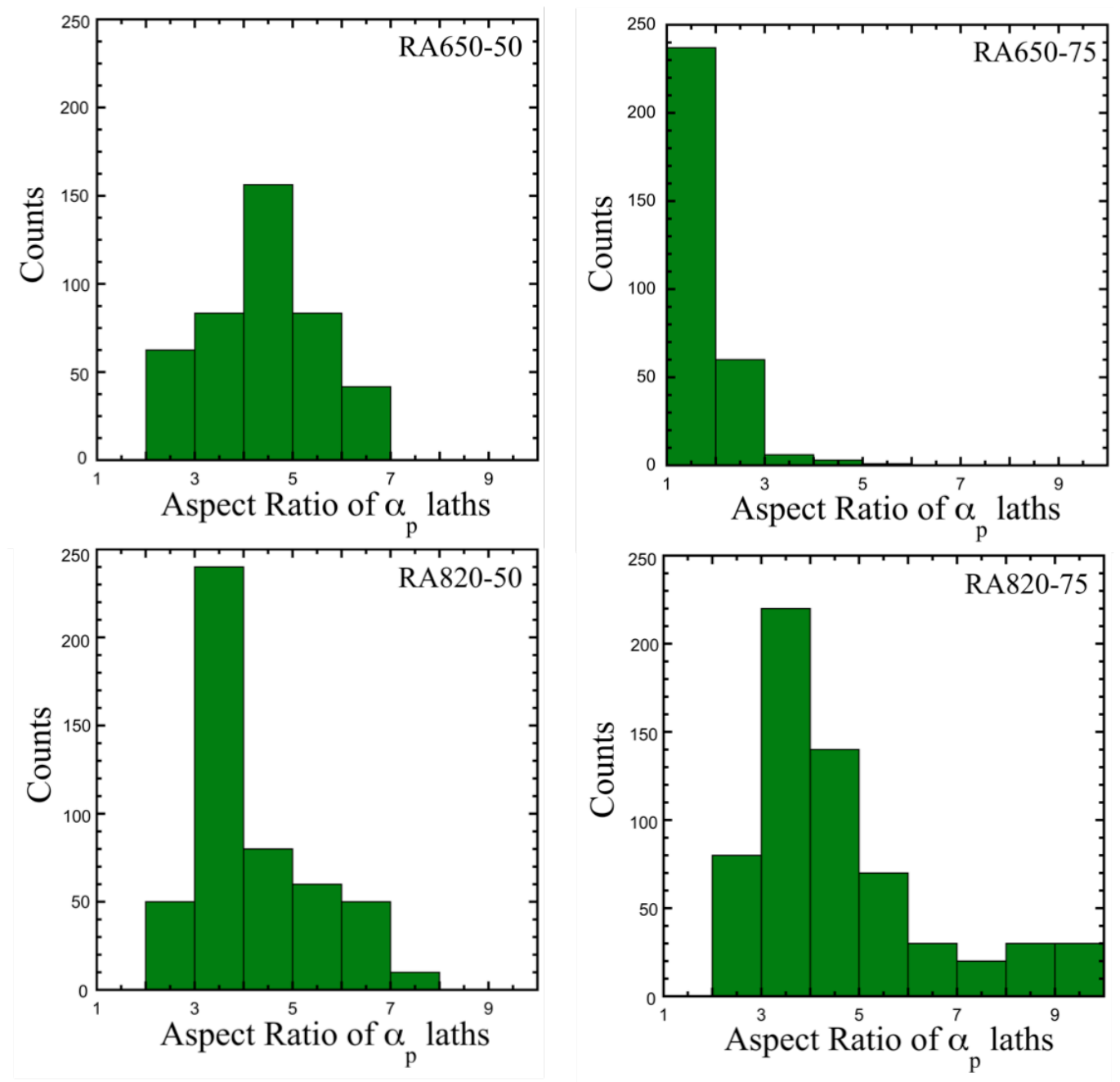

Fig. 8.(a) Variation of primary alpha lath, $\alpha_{p}$, content spherodized in Ti407 in annealed conditions. Corresponding microstructures in RA650-50, RA650-75, RA820-50 and RA820-75 conditions are also shown. Note the phase contrast in these micrographs is primary alpha bright and martensite alpha dark. (b) Histogram plots showing variation of aspect ratio of $\alpha_{p}$ in RA650-50, RA650-75, RA820-50 and RA820-75 conditions. Bin size of the histogram plots is 1. 


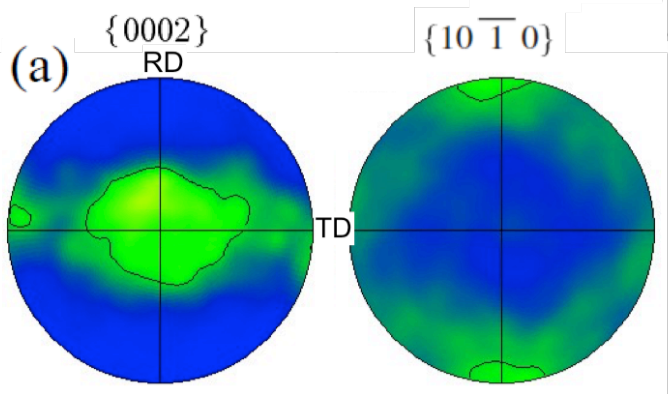

$\mathrm{R} 650-50$

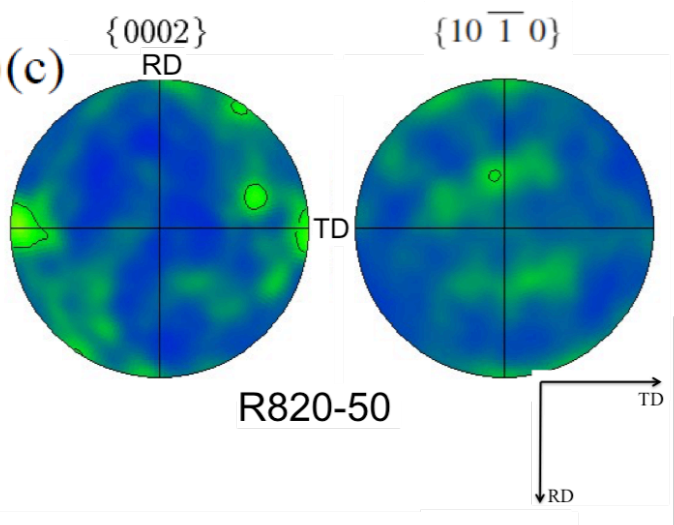

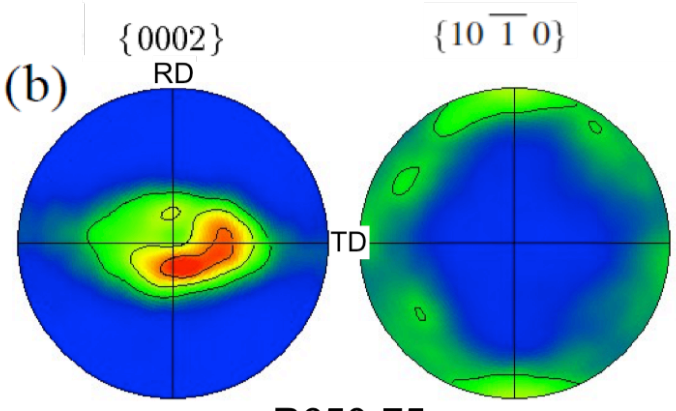

R650-75

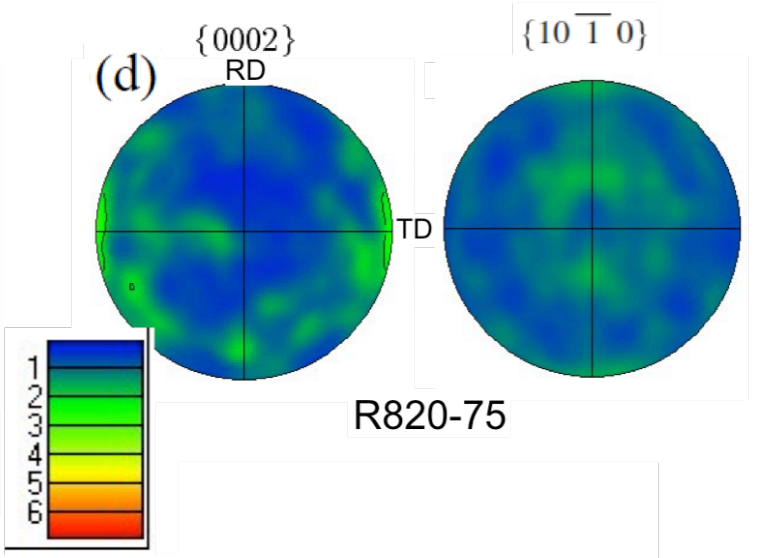

Fig. 9. $\{0002\}$ and $\{10 \overline{1} 0\} \alpha$-phase pole figures of Ti407 in as-rolled conditions. (a) 50 and (b) $75 \%$ rolled at $650{ }^{\circ} \mathrm{C}$, (c) 50 and (d) $75 \%$ rolled at $820{ }^{\circ} \mathrm{C}$. 


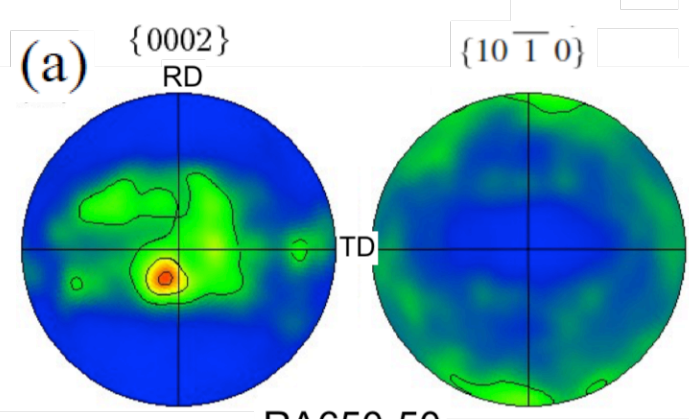

RA650-50

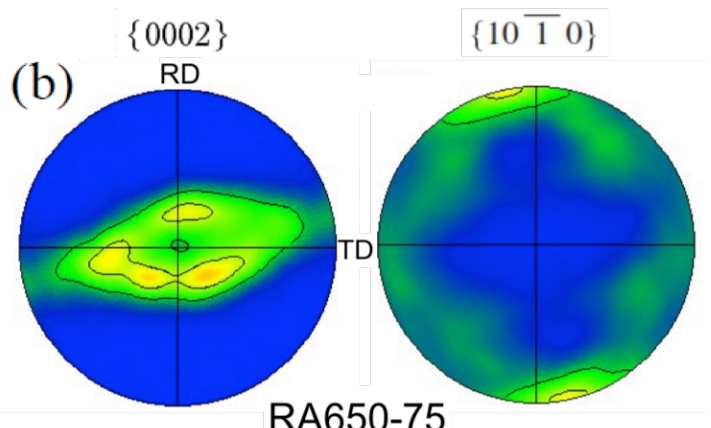

RA650-75
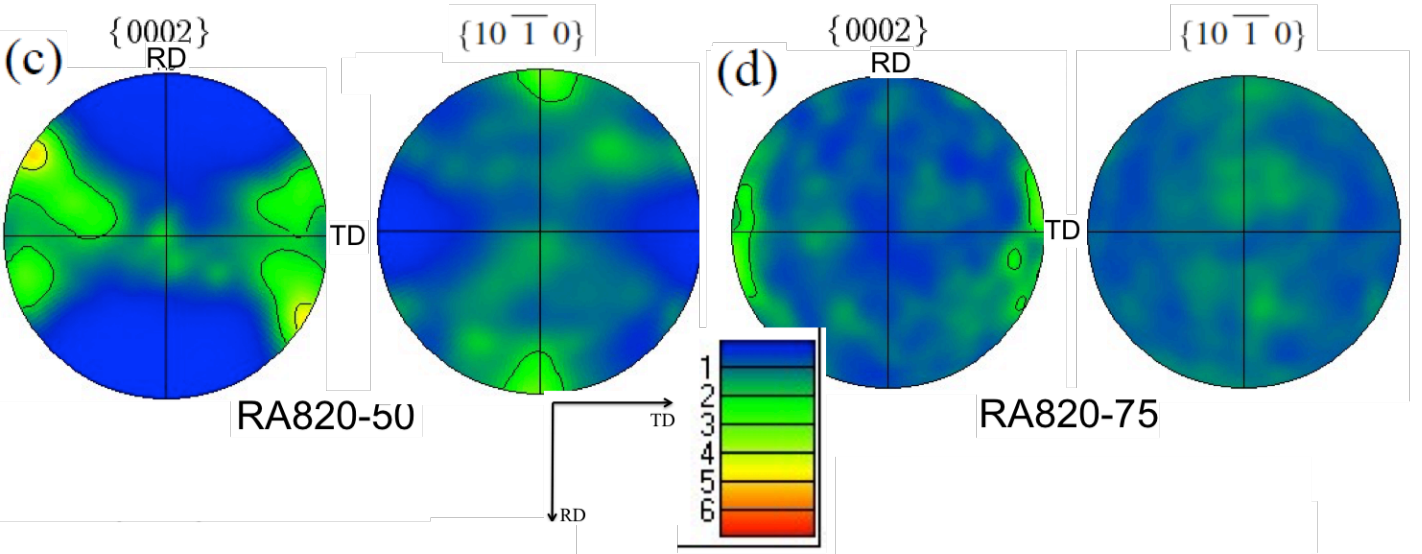

Fig. 10. $\{0002\}$ and $\{10 \overline{1} 0\} \alpha$-phase pole figures of Ti407 in annealed conditions. (a) 50 and (b) $75 \%$ rolled at $650{ }^{\circ} \mathrm{C}$ and annealed at $820{ }^{\circ} \mathrm{C}$ for $8 \mathrm{~h}$, (c) 50 and (d) $75 \%$ rolled at $820{ }^{\circ} \mathrm{C}$ and annealed at $820^{\circ} \mathrm{C}$ for $8 \mathrm{~h}$. 

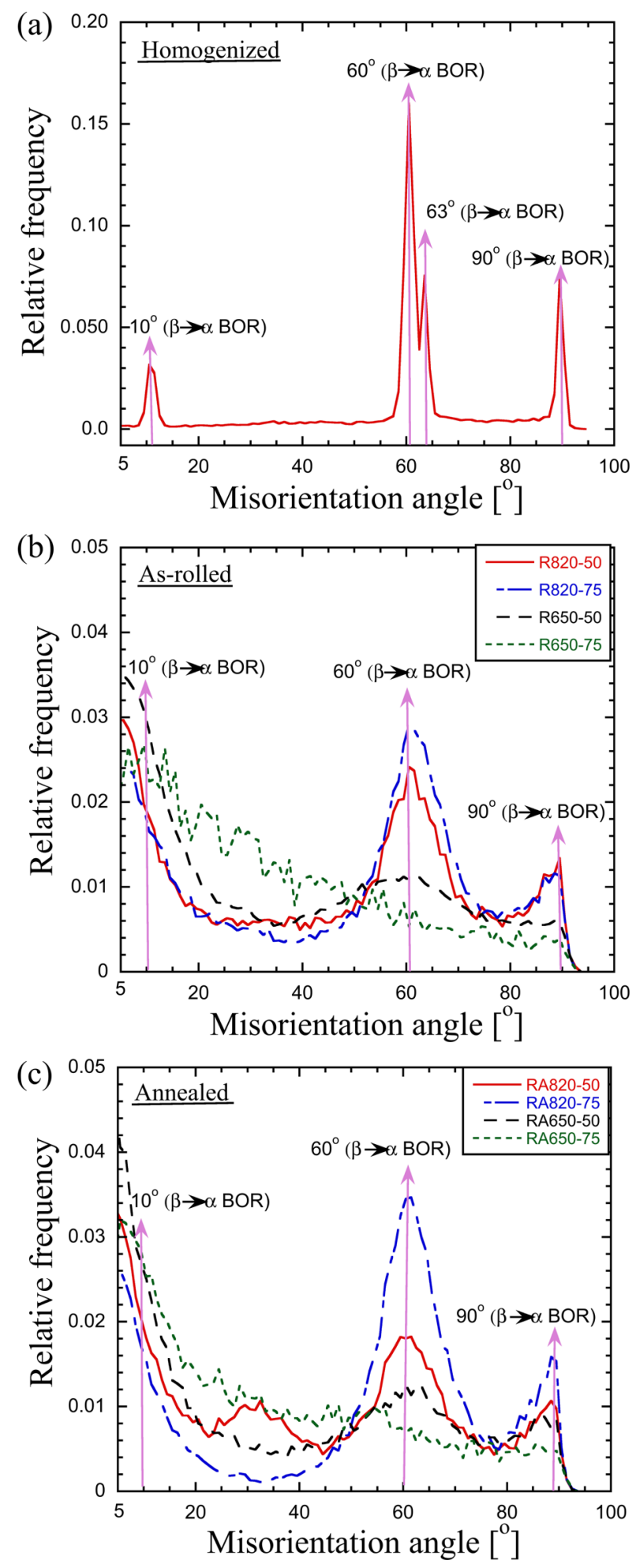

Fig. 11. Relative frequency vs. misorientation angle profiles for Ti407 in (a) homogenized, (b) as-rolled and (c) annealed conditions. 

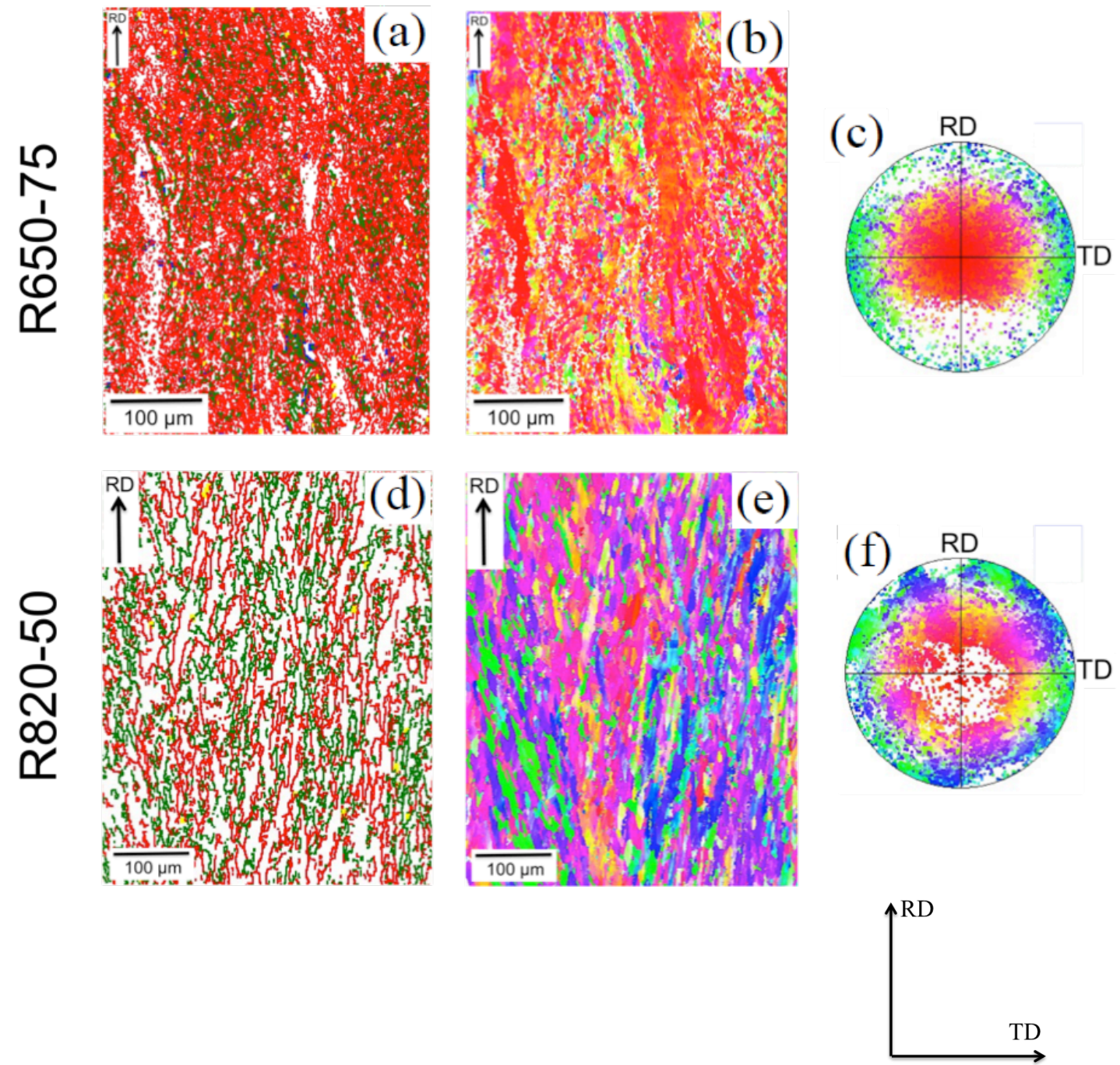

Fig. 12. (a) \& (d) Grain boundary map superimposed with boundaries with misorientation 10,60 and $90^{\circ}$ and are highlighted with red, green and yellow color, respectively, (b) \& (e) IPF and (c) \& (f) $\{0002\} \alpha$-phase PF of Ti407 in as-rolled R650-75 and R820-50 conditions. The $85^{\circ}<11 \overline{2} 0>$ tensile twin boundaries are highlighted with blue color in Fig. 12(a). (For interpretation of the references to color in this figure legend, the reader is referred to the web version of this article.) 

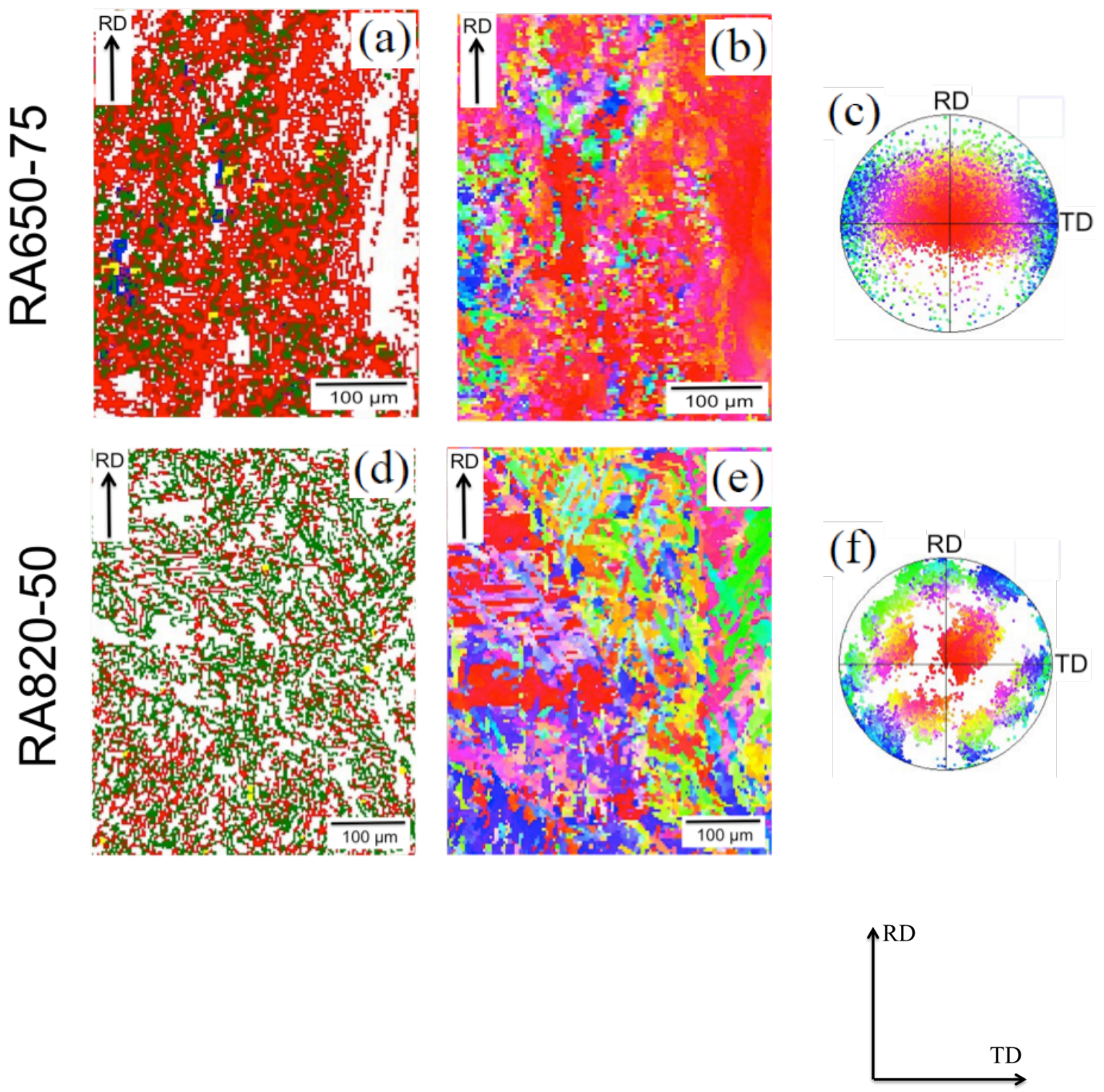

Fig. 13. (a) \& (d) Grain boundary map superimposed with boundaries with misorientation 10,60 and $90^{\circ}$ and are highlighted with red, green and yellow color, respectively, (b) \& (e) IPF and (c) \& (f) $\{0002\} \alpha$-phase PF of Ti407 in annealed RA650-75 and RA820-50 conditions. The $85^{\circ}<11 \overline{2} 0>$ tensile twin boundaries are highlighted with blue color in Fig. 13(a). (For interpretation of the references to color in this figure legend, the reader is referred to the web version of this article.) 

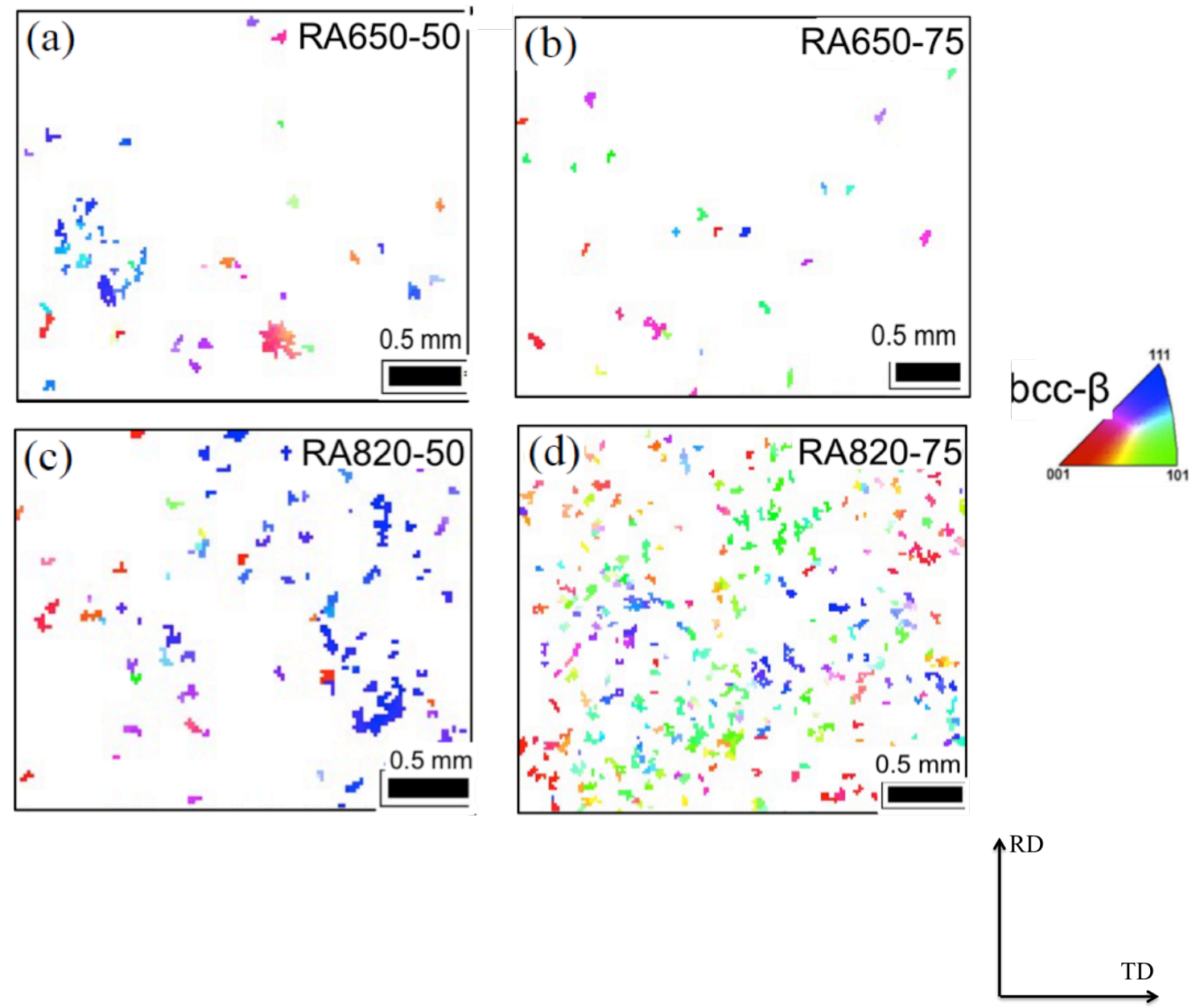

Fig. 14. $\beta$-reconstruction maps of Ti407 in annealed conditions. (a) RA650-50, (b) RA650-75, (c) RA820-50 and (d) RA820-75. (For interpretation of the references to color in this figure legend, the reader is referred to the web version of this article.) 

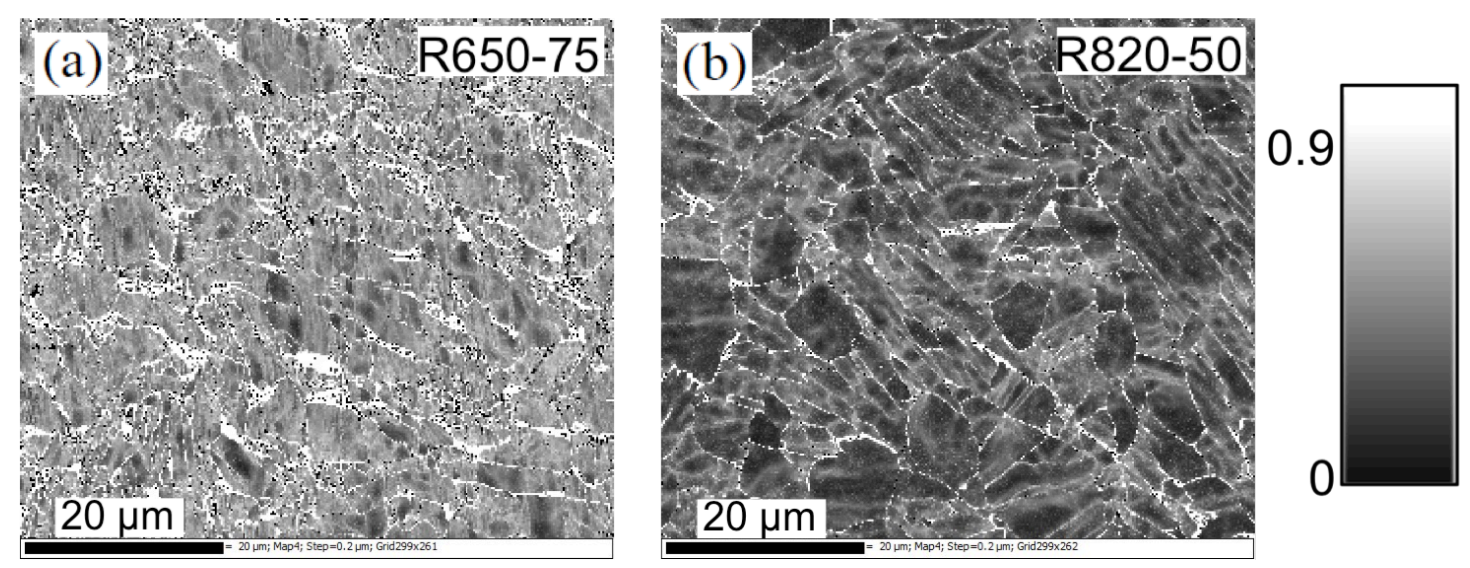

Fig. 15. KAM maps of Ti407 in different conditions. (a) $75 \%$ rolled at $650{ }^{\circ} \mathrm{C}$ and (b) $50 \%$ rolled at $820{ }^{\circ} \mathrm{C}$. KAM maps are obtained using a $5 \times 5$ filter size with subgrain tolerance angle of $1^{\circ}$. Color legend is shown on the right hand side of the figure. 

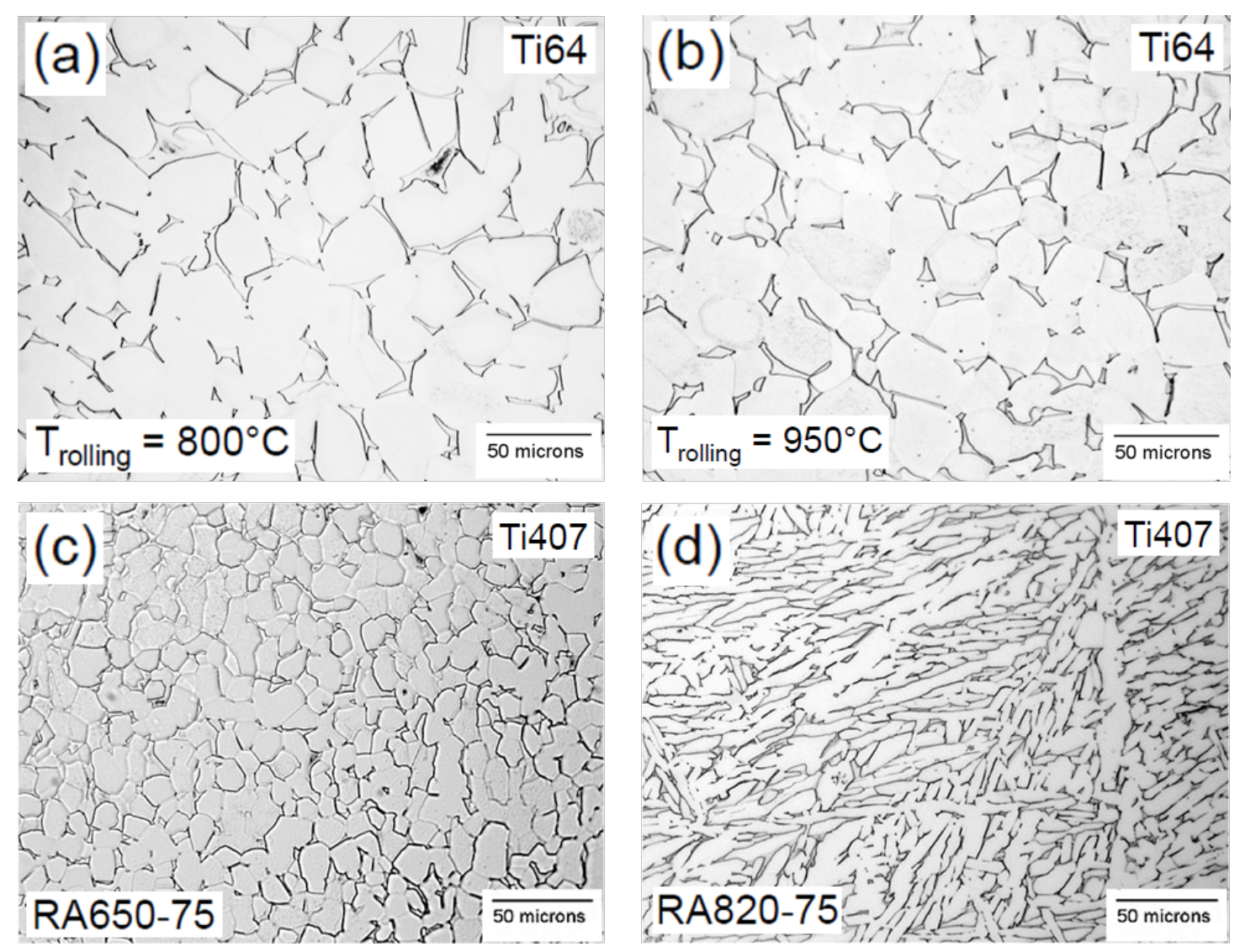

Fig. 16. Optical micrographs of Ti-6Al-4V rolled to $75 \%$ reduction at (a) $800{ }^{\circ} \mathrm{C}$ and (b) $950{ }^{\circ} \mathrm{C}$ followed by annealing at $950{ }^{\circ} \mathrm{C}$ for $8 \mathrm{~h}$ [44]. Optical micrographs of Ti407 in annealed conditions (c) RA650-75 and (d) RA820-75. (a) and (b) reproduced with permission from [44]. 